\title{
AN INVESTIGATIVE STUDY INTO THE RELATIONSHIP OF BONE MORPHOGENETIC PROTEIN ANTAGONIST EXPRESSION AND OSTEOCYTE DENSITY BY REGION AND QUADRANT
}

\author{
A Thesis \\ presented to \\ the Faculty of California Polytechnic State University, \\ San Luis Obispo
}

\author{
In Partial Fulfillment \\ of the Requirements for the Degree \\ Master of Science in Engineering, with a Specialization in Biomedical \\ Engineering \\ by \\ Scott Christopher Mosher \\ April 2010
}


(C) 2010

Scott Christopher Mosher 


\section{ALL RIGHTS RESERVED \\ COMMITTEE MEMBERSHIP}

TITLE:

An Investigative Study into the Relationship of Bone Morphogenetic Protein Antagonist Expression and Osteocyte Density by Region and Quadrant

AUTHOR: $\quad$ Scott Christopher Mosher

DATE SUBMITTED: April 19, 2010

COMMITTEE CHAIR: $\quad$ Scott Hazelwood, Associate Professor

COMMITTEE MEMBER: Lily Laiho, Assistant Professor

COMMITTEE MEMBER: Lanny Griffin, Professor 


\begin{abstract}
An Investigative Study into the Relationship of Bone Morphogenetic Protein Antagonist Expression and Osteocyte Density by Region and Quadrant Scott Christopher Mosher
\end{abstract}

The role of cytokines and cell behavior and viability with respect to bone remodeling and bone behavior is an exciting area of orthopedic research. The purpose of this study was to investigate the relationships between BMP antagonist expression and osteocyte density, lacunar densities and osteocyte viability in cortical bone. Samples of unloaded tibial bone obtained from six C57BI/6 mice were immunohistochemically stained for gremlin and noggin expression and also underwent methyl green staining to determine osteocyte presence. Bone sections were divided into four quadrants (cranial, caudal, medial and lateral) and three regions (proximal, mid shaft and distal), followed by analysis across these quadrants and regions. The results showed matching regional differences in gremlin expression with regional variations in osteocyte density, lacunar density, and osteocyte viability. These variations were supported by positive correlations found via regression analysis. Regression analysis also showed marginal negative correlations between noggin expression and osteocyte density and osteocyte viability, supported by regional ANOVA results. Further research on loaded bone samples is needed if the relationship between these BMP antagonists and osteocyte densities are to be fully explained with respect to the bone remodeling process.

Keywords: BMP, noggin, gremlin, osteocyte density, BMU 


\section{ACKNOWLEDGMENTS}

I would like to thank Dr. Scott Hazelwood for his help, guidance and for giving me the opportunity to work with him. I would also like to thank every member of Dr. Hazelwood's research group for their support, most notably Jessica Chan without whom this thesis may never have been completed. I would also like to thank Drs. Trevor and Kristen Cardinal for their help and advice with the tissue collection, preparation, and training provided with respect to the tissue analysis laboratory as well as Dr. Trevor Cardinal for working with us and providing subjects. Thanks are also due to Dr. Lily Laiho for training and provision of microscope equipment, as well as associated program training.

I would also like to thank my family for their love and support. Mom, Dad --thank you for the encouragement and support through the years even when it sounded like I wasn't doing anything at school.

Finally, I would like to thank the National Institute of Health (NIH Grant \#AR051555) for providing funding for this research. 


\section{Contents}

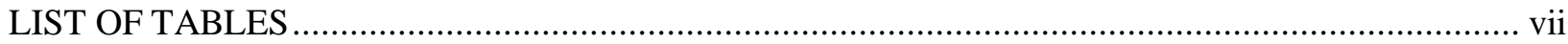

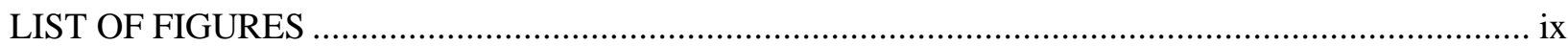

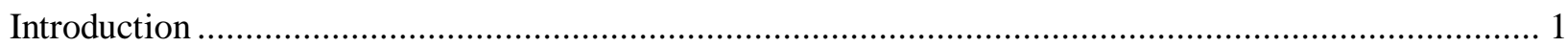

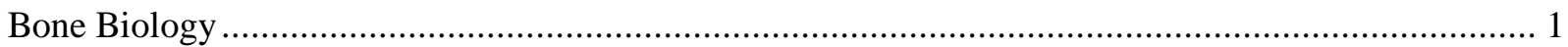

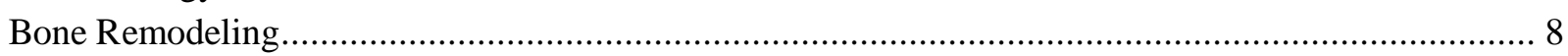

Bone Morphogenetic Proteins and Bone Morphogenetic Protein Antagonists .................................13

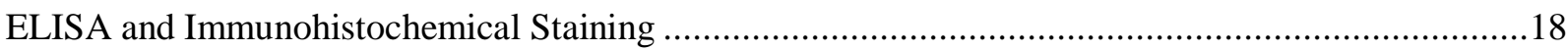

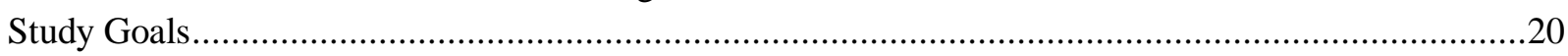

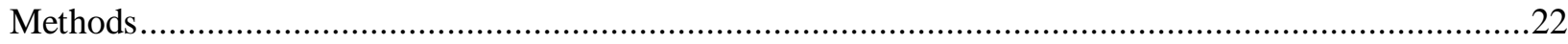

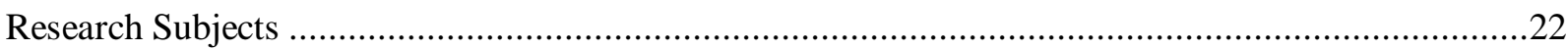

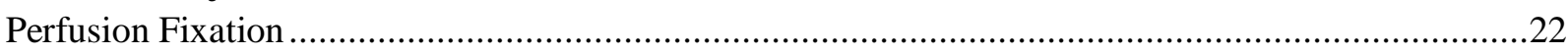

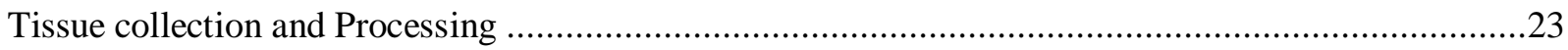

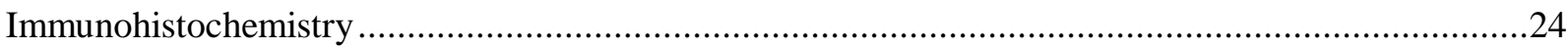

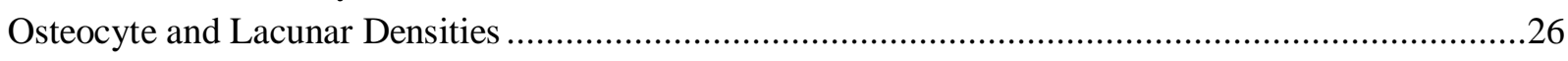

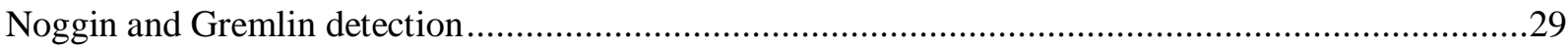

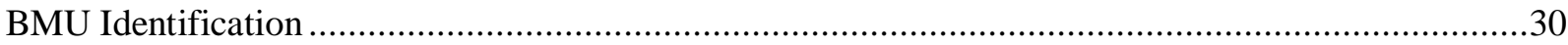

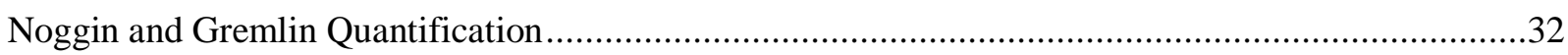

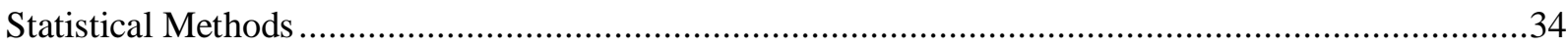

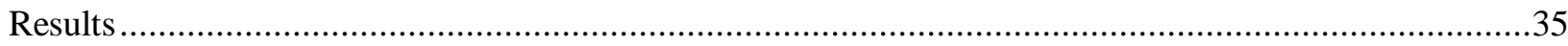

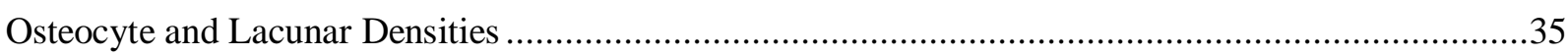

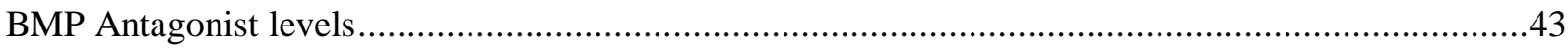

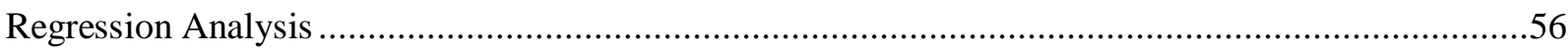

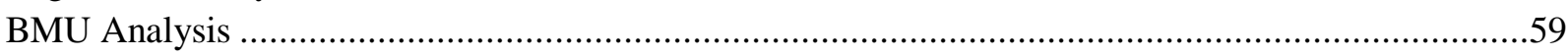

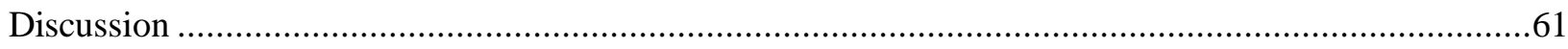

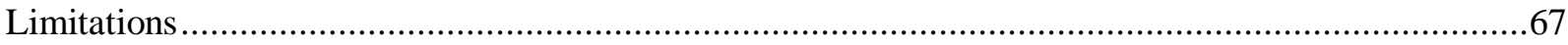

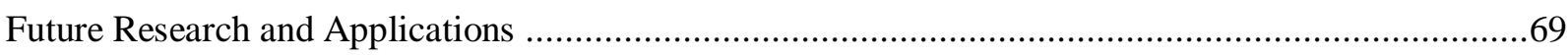

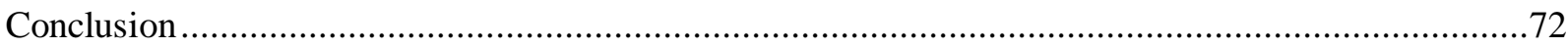

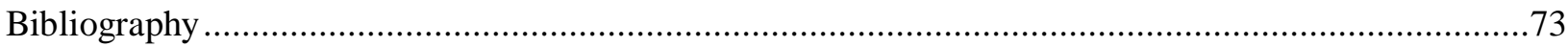

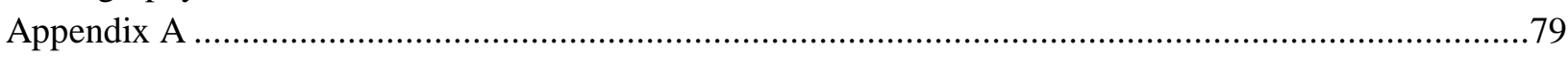

$\mathrm{P}$ values for the differences in Osteocyte Density with respect to the interaction of regions

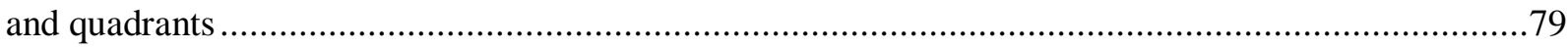

$\mathrm{P}$ values for the differences in Total Lacunar Density with respect to the interaction of

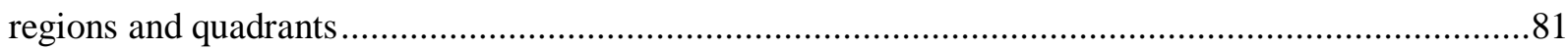

$\mathrm{P}$ values for the differences in the percentage of lacunae containing viable osteocytes with

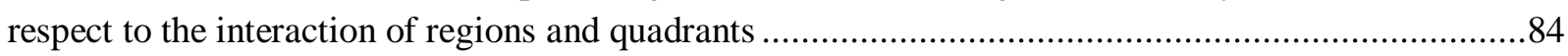




\section{LIST OF TABLES}

Table 1. Osteocyte densities, total lacunar densities, and the percentage of lacunae containing viable osteocytes by individual subjects. Standard deviations in paren....36

Table 2. Quadrantal differences of osteocyte density (OD), total lacunar density (TLD), the percentage of lacunae containing viable osteocytes (\%OD/TLD) across all subjects. Standard deviations in paren.

Table 2a. Quadrantal differences of osteocyte density (OD), total lacunar density (TLD), the percentage of lacunae containing viable osteocytes (\%OD/TLD) across all subjects, data gathered from proximal region only.

Table 2b. Quadrantal differences of osteocyte density (OD), total lacunar density (TLD), the percentage of lacunae containing viable osteocytes (\%OD/TLD) across all subjects, data gathered from midshaft region only.

Table 2c. Quadrantal differences of osteocyte density (OD), total lacunar density (TLD), the percentage of lacunae containing viable osteocytes (\%OD/TLD) across all subjects, data gathered from distal region only.

Table 3. Aggregate data for osteocyte density (OD), total lacunar density (TLD), the percentage of lacunae containing viable osteocytes (\%OD/TLD) for subject 40. 39

Table 4. Aggregate data for osteocyte density (OD), total lacunar density (TLD), the percentage of lacunae containing viable osteocytes (\%OD/TLD) for subject 42.39

Table 5. Aggregate data for osteocyte density (OD), total lacunar density (TLD), the percentage of lacunae containing viable osteocytes (\%OD/TLD) for subject 44. 39

Table 6. Aggregate data for osteocyte density (OD), total lacunar density (TLD), the percentage of lacunae containing viable osteocytes (\%OD/TLD) for subject 88.40

Table 7. Aggregate data for osteocyte density (OD), total lacunar density (TLD), the percentage of lacunae containing viable osteocytes (\%OD/TLD) for subject 90.40

Table 8. Differences in osteocyte density (OD), total lacunar density (TLD), the percentage of lacunae containing viable osteocytes (\%OD/TLD) between quadrants for subject 93 .

Table 9. Regional differences of osteocyte density (OD), total lacunar density (TLD), the percentage of lacunae containing viable osteocytes (\%OD/TLD) across all subjects. Standard deviations in paren.

Table 10. $\mathrm{P}$ values for the difference in average level of noggin expression between quadrants across all subjects. Standard deviations in paren. 
Table 11. $\mathrm{P}$ values for the difference in average level of noggin expression between regions across all subjects. Standard deviations in paren.

Table 12. $\mathrm{P}$ values for the difference in average level of gremlin expression between quadrants across all subjects. Standard deviations in paren.

Table 13. $\mathrm{P}$ values for the difference in average level of gremlin expression between regions across all subjects. Standard deviations in paren.

Table 14a. Differences in average noggin expression (BMPA level) between quadrants for subject 42. Standard deviations in paren.

Table 14b. Differences in average gremlin level (BMPA level) between quadrants for subject 42. Standard deviations in paren.

Table 15. Differences in average bone morphogenetic protein antagonist level (BMPA level) between quadrants for subject 44. Standard deviations in paren. Note: Stained for noggin only.

Table 16. Differences in average bone morphogenetic protein antagonist level (BMPA level) between quadrants for subject 88. Standard deviations in paren. Note: Stained for noggin only.

Table 17. Differences in average bone morphogenetic protein antagonist level (BMPA level) between quadrants for subject 90. Standard deviations in paren. Note: Stained for gremlin only.

Table 18a. Differences in average noggin expression (BMPA level) between quadrants for subject 93. Standard deviations in paren.

Table 18b. Differences in average gremlin expression (BMPA level) between quadrants for subject 93 . Standard deviations in paren.

Table 1. Linearly relationships between BMP antagonist expression and OD, TLD and \%OD/TLD .56

Table 2. Number of BMUs identified across all subjects by both region and quadrant 


\section{LIST OF FIGURES}

Figure 1. Bone anatomy of cortical bone (Martin, et al., 1998).................................. 3

Figure 2. Osteoclast resorbing bone matrix material. Notice the multiple nuclei working in concert (faculty.une.edu/com/abell/histo/osteoclast).................................5

Figure 3. Bone resorption. The mature osteoclasts resorb bone via secretion of hydrochloric acid. The chloride channel ClC-7. Also required to perform resorption are carbonic anhydrase II (CAII), anion exchanger (AE2), $\alpha_{v} \beta_{3}$ integrin, PLEKHM1, OSTM1 and cathepsin K. (Segovia-Silvestre, et al., 2009) .......6

Figure 4. Osteocyte lacunae (A) connected by canaliculi (B) surrounding a central Haversian space (C) (Martin, et al., 1998) ..............................................................

Figure 5. Longitudinal sections of Basic Multicellular Units (BMUs) stained via Gill's Hematoxylin III and Eosin (H\&E). BMUs were identified by the presence of multinucleated osteoclasts and Howship's lacunae at the tips of their cutting cones. (A) Note the presence of lamellae indicating new bone formation around the closing cone. (B) Note the presence of several prominent nuclei in the labeled

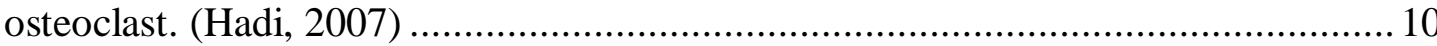

Figure 6. Illustration of the signaling cascade by which bone morphogenetic proteins affect target cells (Balemans \& Van Hul, 2002).

Figure 7. Four primary steps required to perform ELISA. 1) Primary antibody bonds to antigen of interest. 2) Secondary antibody, specific to primary antibody species and Ig super-family bonds to primary antibody. 3) Enzyme complex attaches/engulfs antibody groups. 4) Enzyme substrate bonds to enzyme, marking location and quantity of antigen. (Vectorlabs.com)

Figure 8. Example of ImageJ measurement of bone area. Note A) freehand tool used to outline bone B) bone area displayed C) complete bone area in image field outlined to keep consistent measurements (boarding yellow line)

Figure 9. Example of A) positively stained osteocytes residing in lacunae B) negatively stained (empty) lacunae C) non-specifically stained cells (not in lacunae), not counted toward positive osteocyte count

Figure 10. Newly formed osteon residing within hind murine limb. Note the presence of distinct cement line (denote by arrow) bordering newly formed bone....31

Figure 11. Axial section of a refilling Haversian Basic Multicellular Unit (BMU) found in murine hind tibia. Tissue is unaltered and viewed under white light. Note lamellar bone matrix being refilled by osteoblasts in a radial manner. 
Figure 12. Examples of images depicting the five levels of immunohistochemical staining. From left to right, top to bottom examples show: not detectable, trace staining, weak staining, moderate staining, and strong staining.

Figure 13. Regression analysis of BMP expression vs. osteocyte density. Data from proximal region represented with the symbol $\diamond$ (diamond), mid shaft region represent with the symbol $\bullet$ (circle), distal region represented with the symbol $\boldsymbol{\Delta}$ (triangle). Cranial, caudal, medial and lateral points are color as blue, red, green and gold, respectively. All points indicating noggin levels are solid, while all points indicating gremlin levels are shape outlines only.

Figure 14. Regression analysis of BMP expression vs. osteocyte density. Data from proximal region represented with the symbol $\diamond$ (diamond), mid shaft region represent with the symbol $\bullet$ (circle), distal region represented with the symbol $\boldsymbol{\Delta}$ (triangle). Cranial, caudal, medial and lateral points are color as blue, red, green and gold, respectively. All points indicating noggin levels are solid, while all points indicating gremlin levels are shape outlines only.

Figure 15. Regression analysis of BMP expression vs. osteocyte density. Data from proximal region represented with the symbol $\diamond$ (diamond), mid shaft region represent with the symbol $\bullet$ (circle), distal region represented with the symbol $\boldsymbol{\Delta}$ (triangle). Cranial, caudal, medial and lateral points are color as blue, red, green and gold, respectively. All points indicating noggin levels are solid, while all points indicating gremlin levels are shape outlines only. 


\title{
Introduction
}

\author{
Bone Biology
}

Physiologically, bone has three major functions. First, and most obvious, it provides structure and mechanical support for muscles and locomotion. Second, it provides protection for major organ systems, such as the cardiac and respiratory systems, as well as providing a home and protection for marrow. Finally, it is a storage center for many ions and minerals required for metabolic function, including calcium, phosphorus and a multitude of growth factors (Segovia-Silvestre, et al., 2009). Many early studies concerning bone focused on the role of bone as a mineral reservoir (Martin, et al., 1998). These studies yielded the theory that bone adaptation was controlled by hormones and chemical signals in the body. It was found that blood calcium levels could be regulated by such signals. Parathyroid hormone was found to stimulate the bone cell type known as osteoclasts while calcitonin was found to stimulate osteoblasts, releasing calcium into the blood and depositing calcium in the bone respectively (Martin, et al., 1998). The ideas of bone adaptation have been further expanded as the years have progressed to include both bone modeling and remodeling.

Bone has both an inner and outer surface, known as the endosteum and periosteum respectively, the former of which is covered by a flat lining of cells. The endosteum has three regions in which bone remodeling takes place: the trabecular, endocortical, and Haversian (Jilka, 2003). Trabecular 
bone matter is a highly porous (75-95\%) structure, connected by plates or struts measuring 200 microns thick, called trabeculae, in a three dimensional lattice (Jilka, 2003; Martin, et al., 1998). The nonmineralized pores of trabecular bone provide a home for the body's bone marrow. Bone marrow itself is a tissue composed of blood vessels and nerves and is the source of many of the body's stem cells- including those responsible for blood and bone cells (Martin, et al., 1998). The surfaces of trabecular bone merge into the endocortical, which in turn merge into the Haversian canals of cortical bone (Jilka, 2003). An illustration of bone structure can be found in Figure 1 below. Cortical bone is much less porous than trabecular bone with a porosity of only $5-10 \%$. The pore space of cortical bone is made up of three space types: 1 ) the previously mentioned Haversian canals which run along the long axis of bone, house capillaries and nerves, and measure between 50 and 200 (see Bone Remodeling for further details) microns in diameter 2) the short transverse Haversian connecting spaces called Volksmann's canals and 3) active resorption cavities (measuring near 200 microns in diameter) (Martin, et al., 1998). 


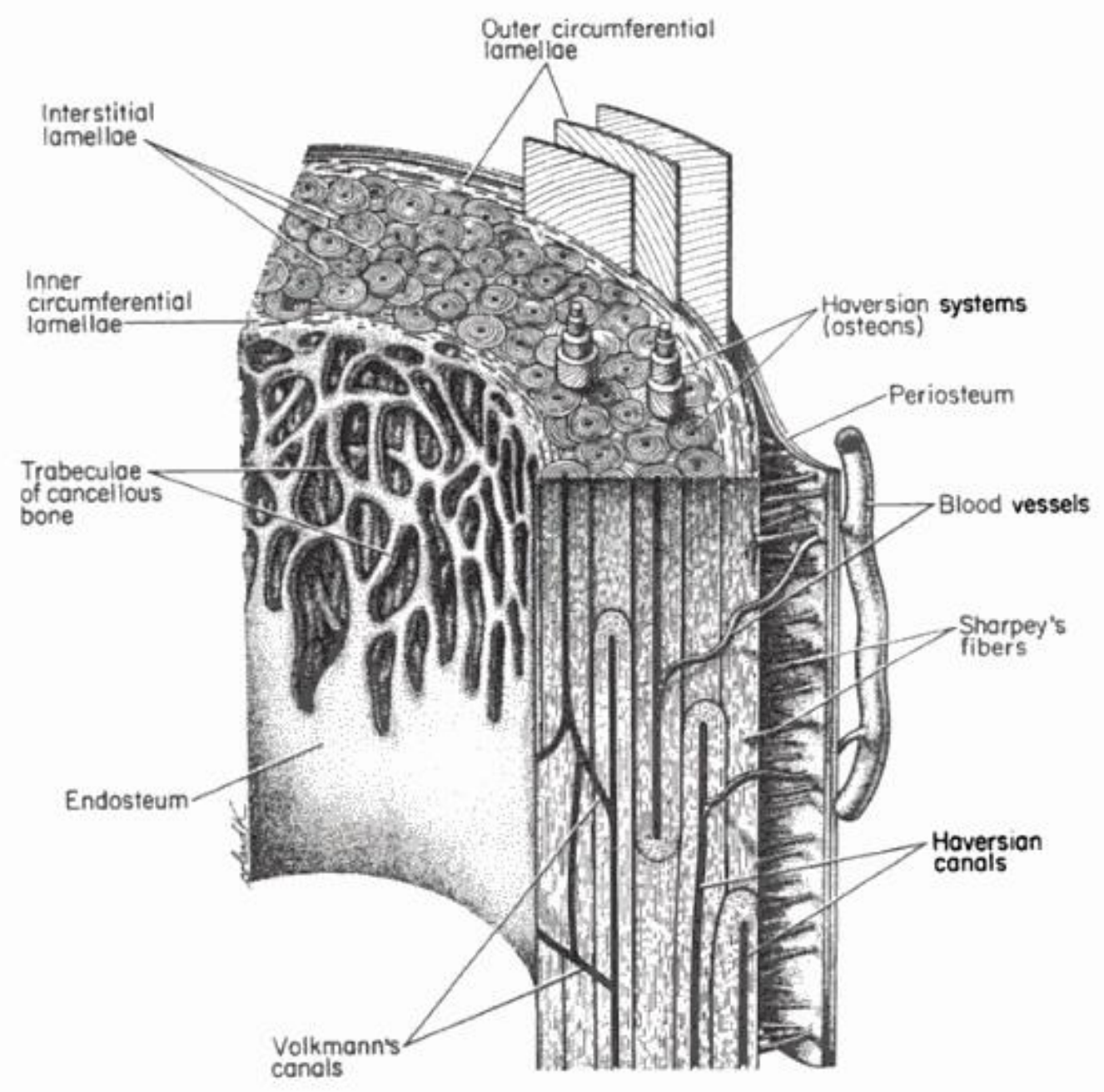

Figure 1. Bone anatomy of cortical bone (Martin, et al., 1998)

The bone matrix itself is predominately composed of 5 materials: collagen (primarily type I), hydroxyapatite $\left(\mathrm{Ca}_{10}\left(\mathrm{PO}_{4}\right)_{6}(\mathrm{OH})_{2}\right)$, proteoglycans, noncollagenous proteins, and water. The matrix is also home to 4 major cell types: osteocytes, osteoblasts, osteoclasts, and bone lining cells (Martin, et al., 1998). Each of these cell types performs a variety of functions within bone, maintaining its physiologic responsibilities. 
Osteoblasts are the cell types responsible for bone matrix formation. Cuboidal in shape, osteoblasts are characterized by having large nuclei, extensive Golgi and endoplasmatic reticulum. These large organelles indicate high levels of protein synthesis (Segovia-Silvestre, et al., 2009). Mature osteoblasts are rarely if ever found alone however; they seem to exist in small clusters consisting of a mix of active bone-forming osteoblasts and their bone lining cell cousins (Segovia-Silvestre, et al., 2009). Bone formation begins as osteoblasts secrete type 1 collagen onto existing bone surfaces. This newly formed matrix is composed of unmineralized bone matrix, referred to as osteoid, and is laid down at a rate of about 1 micron a day (Martin, et al., 1998; Segovia-Silvestre, et al., 2009). Once the osteoid is formed, osteoblasts begin to mineralize this newly formed bone along the mineralization or calcification front by secreting vesicles which contain concentrations of calcium and phosphate in high enough levels to allow crystal formation, while also removing some of the water content (Manolagas, 2000). Secretion of additional molecules required for correction matrix mineralization is also performed by this cell type. These include: osteocalcin, osteopontin, osteonection, and bone sialoprotein (Segovia-Silvestre, et al., 2009).

Once their tasks are complete, osteoblasts have three potential cell fates. Approximately $5 \%$ develop in bone lining cells, $25 \%$ develop into osteocytes, with the remaining $70 \%$ undergoing cell death via apoptosis (Manolagas, 2000). 
Osteoclasts are larger than their bone forming counterparts and are composed of multiple nuclei (Figure 2). Originated from hemopatoatic stem cells (Marks \& Walker, 1981), osteoclasts differentiation requires early steps similar to those of monocytes and macrophages (Roodman, 2006).

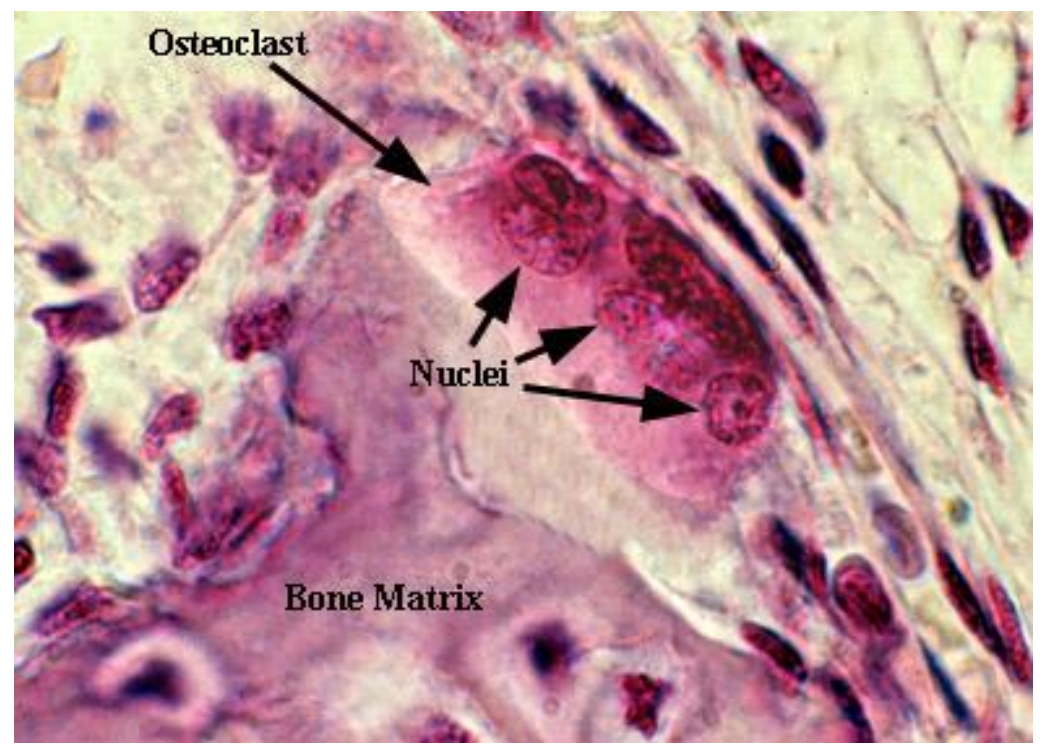

Figure 2. Osteoclast resorbing bone matrix material. Notice the multiple nuclei working in concert (faculty.une.edu/com/abell/histo/osteoclast)

These large cells are responsible for resorbing old or unused bone, releasing minerals that can be transported throughout the body (Roodman, 1999). Resorption begins along the brush or ruffled borders of the osteoclasts as protons are secreted by a specific ATPase in conjunction with passive transport of chloride ions (Figure 3) (Martin, et al., 1998; Segovia-Silvestre, et al., 2009). Catalyzation of carbon dioxide and water into $\mathrm{H}_{2} \mathrm{CO}_{3}$, followed by catalyzation into $\mathrm{H}+$ and $\mathrm{HCO}_{3}$, generates these ions within the cells 
(Segovia-Silvestre, et al., 2009). These secretions combine into hydrochloric acid, lowering the $\mathrm{pH}$ of the surrounding matrix to approximately 4.5 . The $\mathrm{pH}$ reduction then leads to dissolution of the inorganic matrix of bone. $\mathrm{pH}$ activated cysteine proteinase cathepsin $\mathrm{K}$ works in conjunction with the bonedissolving acid to cleave and remove the type I collagen fibers (SegoviaSilvestre, et al., 2009). Resorbed materials are finally removed via transcytosis through the osteoclasts.

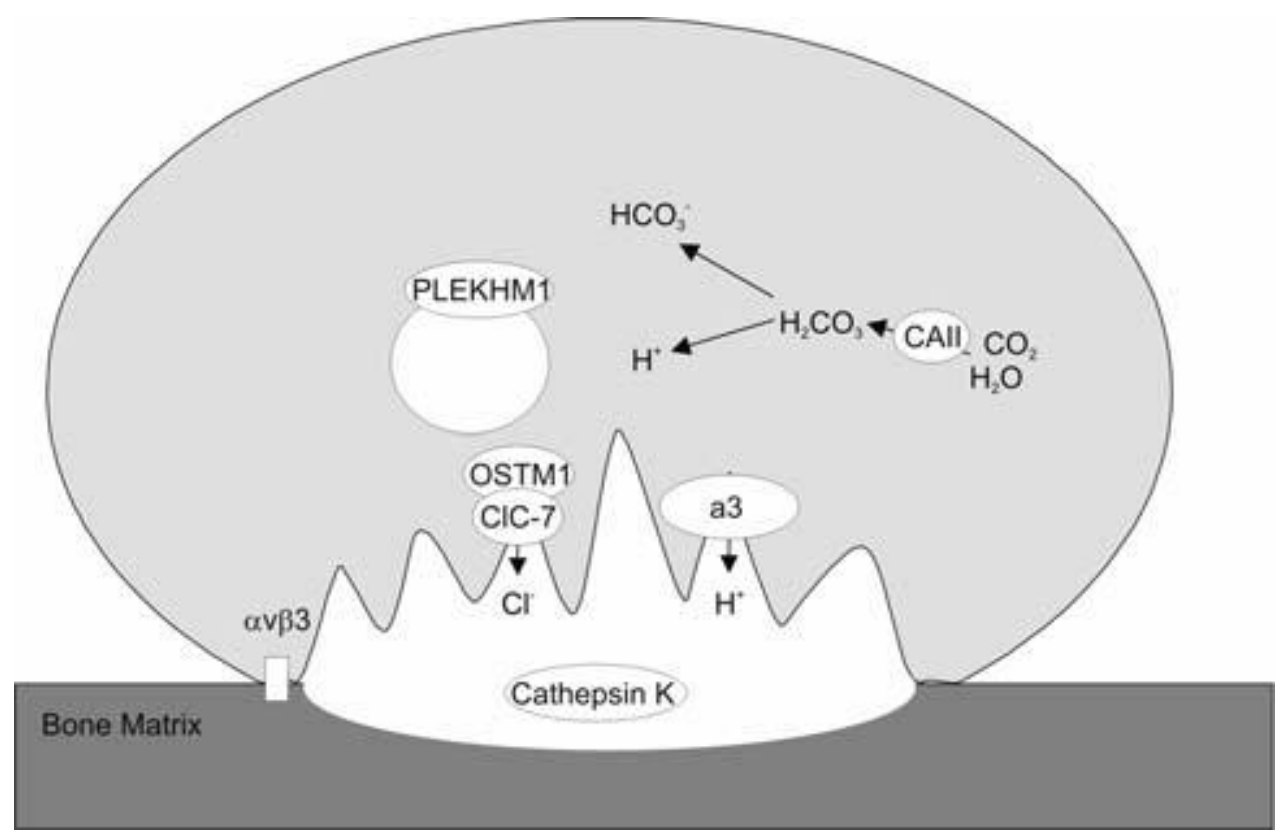

Figure 3. Bone resorption. The mature osteoclasts resorb bone via secretion of hydrochloric acid. The chloride channel ClC-7. Also required to perform resorption are carbonic anhydrase II (CAII), anion exchanger (AE2), $\alpha_{v} \beta_{3}$ integrin, PLEKHM1, OSTM1 and cathepsin K. (Segovia-Silvestre, et al., 2009) 
As mentioned before, bone lining cells and osteocytes are relatives of osteoblasts. However, while they potentially come from a common lineage, the two cell types possess their own responsibilities. Osteocytes are osteoblasts that have become permanently differentiated and are now embedded in the bone matrix. The spaces in which they reside are known as lacunae, of which there can be as many as 15,000 per cubic millimeter of bone (Martin, et al., 1998). The lacunae are further connected by other tunnels in the matrix known as canaliculi (Figure 4). These canaliculi contain cellular processes from neighboring osteocytes, implying communication between cells via chemical signals jumping across gap junctions (Martin, et al., 1998).

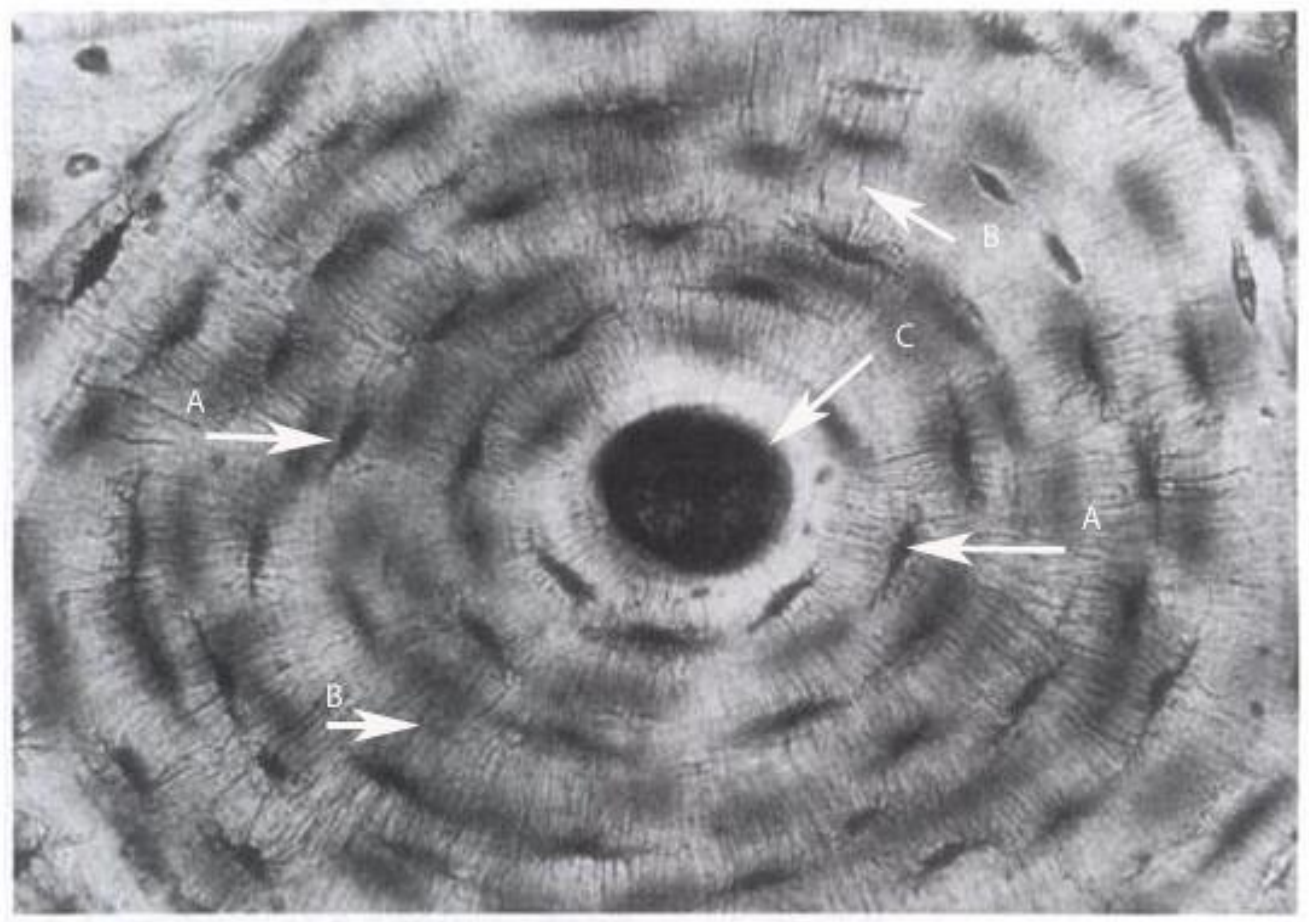

Figure 4. Osteocyte lacunae (A) connected by canaliculi (B) surrounding a central Haversian space (C) (Martin, et al., 1998) 
Osteocytes play many roles in bone, of which sensing mechanical changes, including fluid flow, substrate strain, membrane deformation, integrin stimulation, vibration, altered gravity, and compressive loading, may be the most important (Papachroni, et al., 2009). Many believe that the mechanotransductive abilities of osteocytes are key to the initiation of bone remodeling (Papachroni, et al., 2009). The mechanical changes are sensed by osteocytes in the neighboring area of bone and are then converted into electrical or biochemical signals. Three coupled processes must take place for this to occur: mechanosensing, signal transduction and effector-cell response (Papachroni, et al., 2009). When one or more of the mechanosenors is triggered, intracellular enzymes are activated, as well as secretion of growth factors that regulate local osteogenesis (Papachroni, et al., 2009). These changes activate transcription factors, promoting osteoblast differentiation.

Bone lining cells, our fourth and final cell type, are differentiated osteoblasts that remain on bone surfaces - endosteal, periosteal and Haversian. They communicate with osteocytes embedded within the bone matrix and may play a role in mineral transfer and the sensing of mechanical strain.

\section{Bone Remodeling}

The modification of bone structure and composition falls into three categories - osetogenesis, bone modeling and bone remodeling. The latter 
two can be differentiated by the interaction of bone forming and resorbing cells. While bone modeling is the sculpting of a bone's size and shape by independent osteoblast and osteoclast activity in separate regions of bone, bone remodeling requires coupled action of osteoblasts and osteoclasts to repair fatigue damage or change the internal architecture of bone (Martin, et al., 1998; Papachroni, et al., 2009). The birth of bone remodeling research is commonly credited to a Julius Wolff worked published in 1892. In this work, Wolff states that bones will adapt to the loads placed on them (Wolff, 1986). The process by which osteoclasts and osteoblasts work together to remodel bone has been further defined and refined over the past century.

Basic multicellular units (BMUs) are composed of groups of osteoclasts and osteoblasts working in concert, as well as osteocytes, bone lining cells, precursors of the bone cells and endothelial and nerve cells (Figure 5) (Papachroni, et al., 2009). Coined by Harold Frost in the 1960's, a BMU is often composed of hundreds of osteoblasts and tens of osteoclasts and usually measures near 200 microns in diameter. Frost was the first to deduce that osteoblasts and osteoclasts usually work in concert while adapting bone rather than working separately to singularly maintain blood calcium levels (Martin, et al., 1998). 

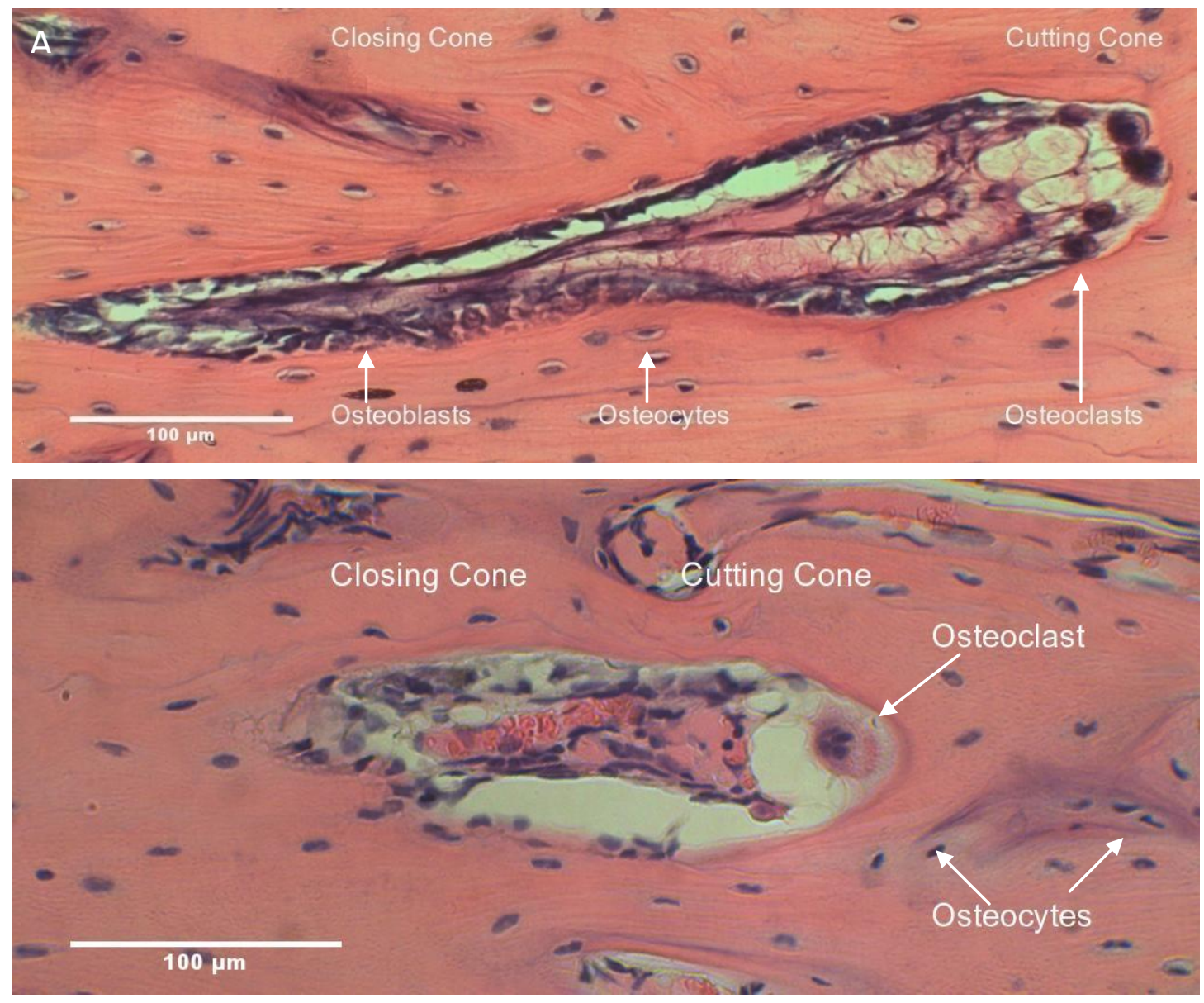

Figure 5. Longitudinal sections of Basic Multicellular Units (BMUs) stained via Gill's Hematoxylin III and Eosin (H\&E). BMUs were identified by the presence of multinucleated osteoclasts and Howship's lacunae at the tips of their cutting cones. (A) Note the presence of lamellae indicating new bone formation around the closing cone. (B) Note the presence of several prominent nuclei in the labeled osteoclast. (Hadi, 2007)

As bone ages and undergoes the repetitive mechanical stresses associated with movement, it loses some of its structural integrity. Bone is 
replaced by these BMUs as the osteoclasts resorb the old or damaged bone and the osteoblasts lay down new bone in their wake (Jilka, 2003). Because of the relatively short life span of the bone resorbing and forming cells, they must be continually replaced as a BMU moves through bone (Manolagas, 2000; Papachroni, et al., 2009). By comparison, osteoclasts and osteoblasts typically enjoy a lifespan in a period of weeks while it has been shown that BMU advance in adult human bones may last for as long as 6 months, progressing at a rate of about 40 microns/day (Jaworski, 1992; Martin, et al., 1998). Interestingly, the spatial distances between cells within each unit stay constant for the entirety of the remodeling process.

BMU activation is locally controlled by groups of cytokines, including bone morphogenetic proteins (bone growth promoters) and chemotaxins (cell migration regulators), as well as growth factors (Martin, et al., 1998). Once a BMU has been activated, it can take several days for the osteoclasts to form at the point of origin. In cortical bone, these newly formed resorbing osteoclasts begin removing bone along the long axis of the bone, either traveling distally, proximally or both (Jilka, 2003; Martin, et al., 1998). These newly formed osteoclasts reside in the cutting cone of the BMU, an area approximately 200 microns in diameter and 300 microns long, eventually creating a cavity called a resorption space. A period of reversal in a BMU follows the tunneling osteoclasts before the refilling osteoblasts reach the cavity. This reversal period last only a few days, then the formation period of a BMU's life begins. Osteoblasts refill the resorption space by laying down 
concentric lamellae at an average rate of 1 to 2 radial microns per day, slowing as the space becomes more filled (Martin, et al., 1998). This newly remodeled bone, each individually referred to as an osteon, can be clearly identified by this radial lamellae and the line at which the new and old bone meet, known as the cement line (Martin, et al., 1998; Papachroni, et al., 2009). None of this can be done without proper vascularization of the working cells, so space for capillaries must be maintained. The osteoclasts receive and dispose of waste via capillaries in the cutting cone, while the osteoblasts leave a space in the center of a forming osteon called the Haversian canal to provide vascularization. As such, BMUs in cortical bone are sometimes referred to as Haversian BMUs.

Because the osteoclasts primarily resorb along the long axis of the bone, the Haversian canals' orientation make it possible to capture images in profile of BMUs along the longitudinal axis of bone as they make their way through the bone matrix (Jilka, 2003). Remodeling in trabecular bone follows the same stages as that in cortical bone but because of the small size of trabeculae, a BMU must dig and refill trenches in the bone. As such, and because of the complex geometry and random orientation of trabeculae, it is extremely hard to capture an image of a active BMU in trabecular bone (Jilka, 2003). 
Bone Morphogenetic Proteins and Bone Morphogenetic Protein Antagonists

The role bone morphogenetic proteins (BMPs) play throughout the body has been an exciting area of research in recent years. Members of the TGF-beta family of proteins, BMPs have been shown to play roles in early and adult neural cell development and neurogenesis, a possible regulator of prostate cancer, a key regulator of bone fracture healing (including initiation, healing speed and healing strength), as well as a role in general homeostasis and the development of vertebrate organs and tissues (Dean, et al., 2009; Haudenschild, et al., 2004; Lim, et al., 2000; Lories, et al., 2006; Rosen, 2006; Xin, et al., 2006). In fact, many diseases have been linked to inborn defects in BMP signaling, whether over or underactive (Cuny, et al., 2008). There are currently more than two dozen identified BMPs active and present in the human body, each performing a subset of activities with differing expression patterns (Haudenschild, et al., 2004; Wang, et al., 2006). As far as their role in bone, the family of proteins originally was identified in the 1960s by their ability to induce formation of new bone when implanted at ectopic subcutaneous sites in rats (Dean, et al., 2009; Haudenschild, et al., 2004; Rosen, 2006). They do so by recruiting progenitor stem cells and initiating growth and differentiation into bone through a series of events similar to that seen in embryogenesis (Reddi, 1998). They also play a role in limb growth, possibly by triggering apoptosis in areas of developing limbs, sculpting them to the geometric needs (Merino, et al., 1999). 
BMP signaling is mediated by two types of serine-threonine kinase receptors known as types I and II receptors (Haque, et al., 2008). BMP ligand must bind to a combination of two type I receptors and two type II receptors for signal transduction to be initiated (Figure 6). This binding induces phosphorylation of the type I receptor by the type II receptor (Balemans \& Van Hul, 2002). Type I receptors then interact with a group of intracellular signaling factors known as Smads.

extracellular

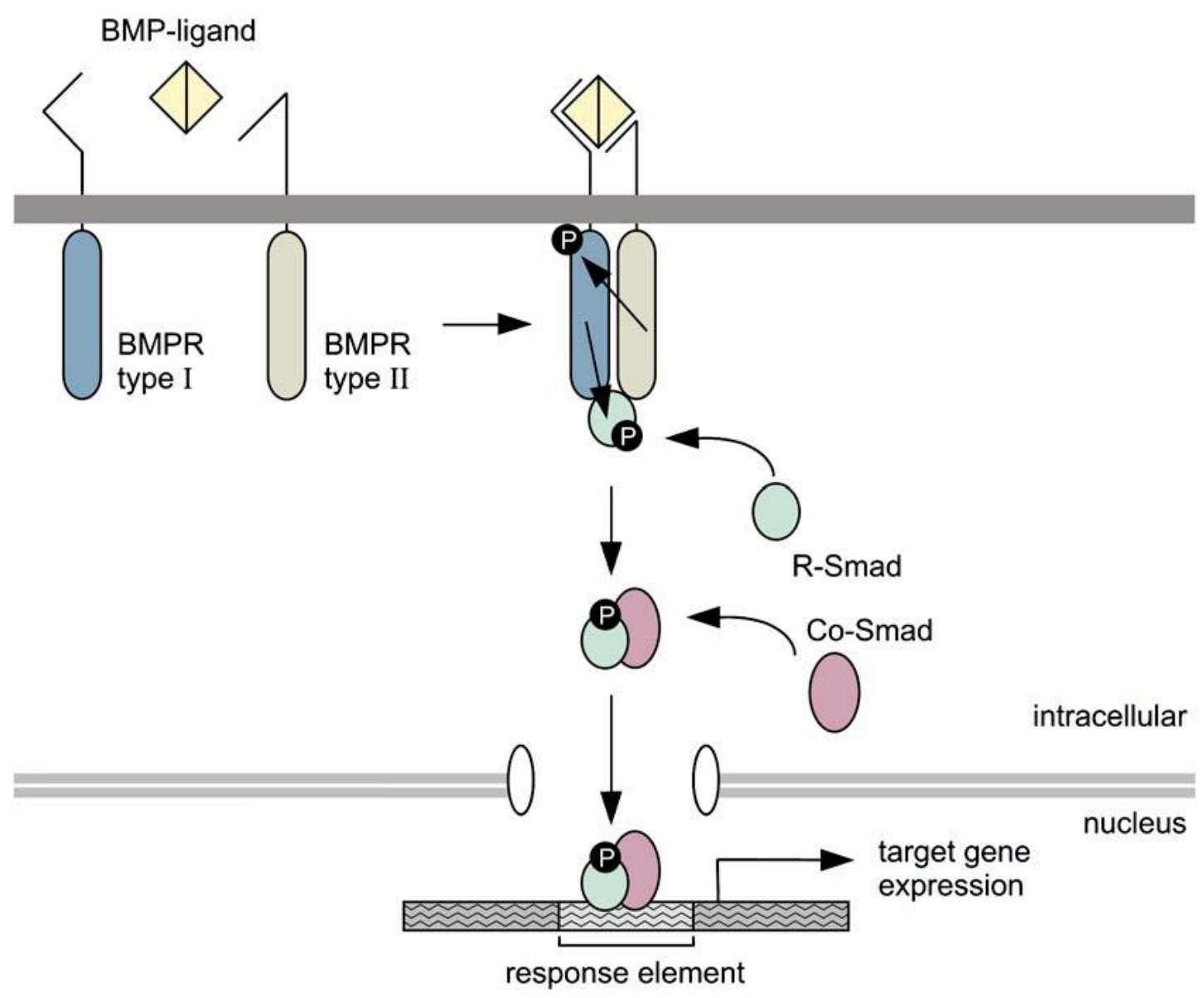

Figure 6. Illustration of the signaling cascade by which bone morphogenetic proteins affect target cells (Balemans \& Van Hul, 2002). 
These Smads, specifically Smads $-1,-5$, and -8 (receptor-regulated Smads), undergo chemical changes and then translocate into the nucleus, where the completed signaling complex either interacts with various factors or binds directly to DNA (Balemans \& Van Hul, 2002; Haque, et al., 2008).

As with many cell signaling factors, BMPs function's can be regulated along any step of the signaling cascade - either extracellularly, at the cell membrane or intracellularly (Montero, et al., 2008). One such regulation method is another family of cytokines referred to as bone morphogenetic protein antagonists, examples of which include noggin, gremlin, follistatin, and sclerostin. BMP antagonists' inhibitory nature, with respect to BMP function, stems from the binding these secreted proteins perform. At the extracellular level, BMP antagonists bind to nearby BMPs, reducing their bioavailability to interact with type I and type II bone morphogenetic protein receptors on target cells (Haudenschild, et al., 2004). Other regulatory mechanisms interact at the membrane and intracellular levels, such as kinase-deficient receptor mimics and inhibitory Smads, respectively (Haudenschild, et al., 2004). However, the inhibitory nature of antagonists is necessary, as studies with knockout mice have shown that, specifically with noggin, such mice have malformed limbs, stunted or improper skeletal growth, or undersized neural anatomy (Balemans \& Van Hul, 2002; Nissim, et al., 2006). Conversely, when the levels of antagonists are abnormally elevated, it has been shown that general mice skeletal growth becomes stunted as well as evidence showing deviation in limb maturation in avian models from normal skeletal 
development (Gazzerro, et al., 2005; Merino, et al., 1999). These studies indicate the need for a delicate balance between BMPs and their antagonists for proper overall growth.

As previously mentioned, bone remodeling is a series of events designed to allow bone to repair small amounts of damage naturally accumulated over time. For the process to occur, a group of osteoclasts must first be initiated. The entire process of bone remodeling after initiation to cavity refilling is well understood, as are the cell types involved. What is not yet fully understood is the signaling pathway that informs bone cells of mircodamage. However, there are several existing theories for the initiation of bone remodeling. One theory suggests that the mechanosensing abilities of osteocytes directly influence remodeling initiation. Another theory suggests variations in BMP or BMP antagonist levels. This variation could either come about from mechanical changes in bone or stimulatory events. The mechanical stimuli attributed with direct influence of bone remodeling have also been shown to be associated with changes in the homeostasis of hormones in the neighboring areas (Mitsui, et al., 2006). Specifically, excessive compressive forces on osteoblasts induce expression of extracellular antagonists of BMPs, inhibiting osteoblastogenesis (Mitsui, et al., 2006). Another possible pathway for cell signals is associated with osteocyte apoptosis, whereby the dead osteocytes have either stopped releasing their cell signal factors or released a large amount of different factors as they perish. 
The idea of local BMP variation leading to a possible mechanism for remodeling of bone and cartilage could be explained by either a local increase in the levels of BMPs or a local decrease in the levels of BMP antagonists. However, this theory has not been fully researched or tested in either tissue. It has been shown that noggin has inhibitory effects on BMPs-2, $-4,-5,-6$, and -7 and is upregulated by these same BMPs as a bone overgrowth regulatory controller, while gremlin has inhibitory effects on BMPs-2, -4, and -7 (Ahn, et al., 2003; Dean, et al., 2009; Haudenschild, et al., 2004). In fact, it has been shown that noggin, as well as other antagonists including gremlin, are products of osteoblasts themselves and are produced as osteoblastic BMPs rise (Gazzerro, et al., 2005; Rosen, 2006).

BMPs-2, -4 and -7 have all been shown to be potent bone inducers, so looking at the levels of antagonists known to inhibit these proteins may lead to further understanding of the interplay between them and general bone behavior (Nakamura, et al., 2003). This interplay has been shown to be extremely important, an example of which was shown in a 2003 study where patients feedback loop for antagonists no longer properly functioned, leading to skeletal muscle tissue being replaced by overactive osteoblasts with skeletal bone tissue (Ahn, et al.). They have also been shown to induce the differentiation of osteoblast progenitors into osteoblasts, an important step in the remodeling process (Gazzerro, et al., 2005). 


\section{ELISA and Immunohistochemical Staining}

An ELISA, or Enzyme-Linked ImmunoSorbent Assay, is a technique used to detect an antibody or antigen in serum sample. Antigens can be a variety of biologic substances, including proteins and cytokines.

To begin an ELISA, the surface must be coated in the antigen(s) of interest. This is accomplished by introducing a serum with the antigen, among other substances, into a series of wells. The four major steps of an ELISA are shown in the figure below (Figure 7). First, a primary antibody specific to the antigen of interest needs to be introduced. The variable end of these antibodies bind to the antigen, leaving their constant regions exposed. Next, a secondary antibody with variable regions specific to the exposed constant regions of the primary antibody used --- for example an immunoglobulin $\mathrm{G}(\lg \mathrm{G})$ goat specific antibody --- binds to the constant region of the primary antibody. Next, this antibody is linked to an enzyme. Again, the enzyme complexes change based on the type of antibody used, as well as the substrate being used in step four. For the final step, an enzyme substrate is added to the entire antibody-enzyme complex. Substrates emit a specific color, many of which fluoresce. From this fluorescence, the amount of antigen can be inferred by the intensity of color emitted. 

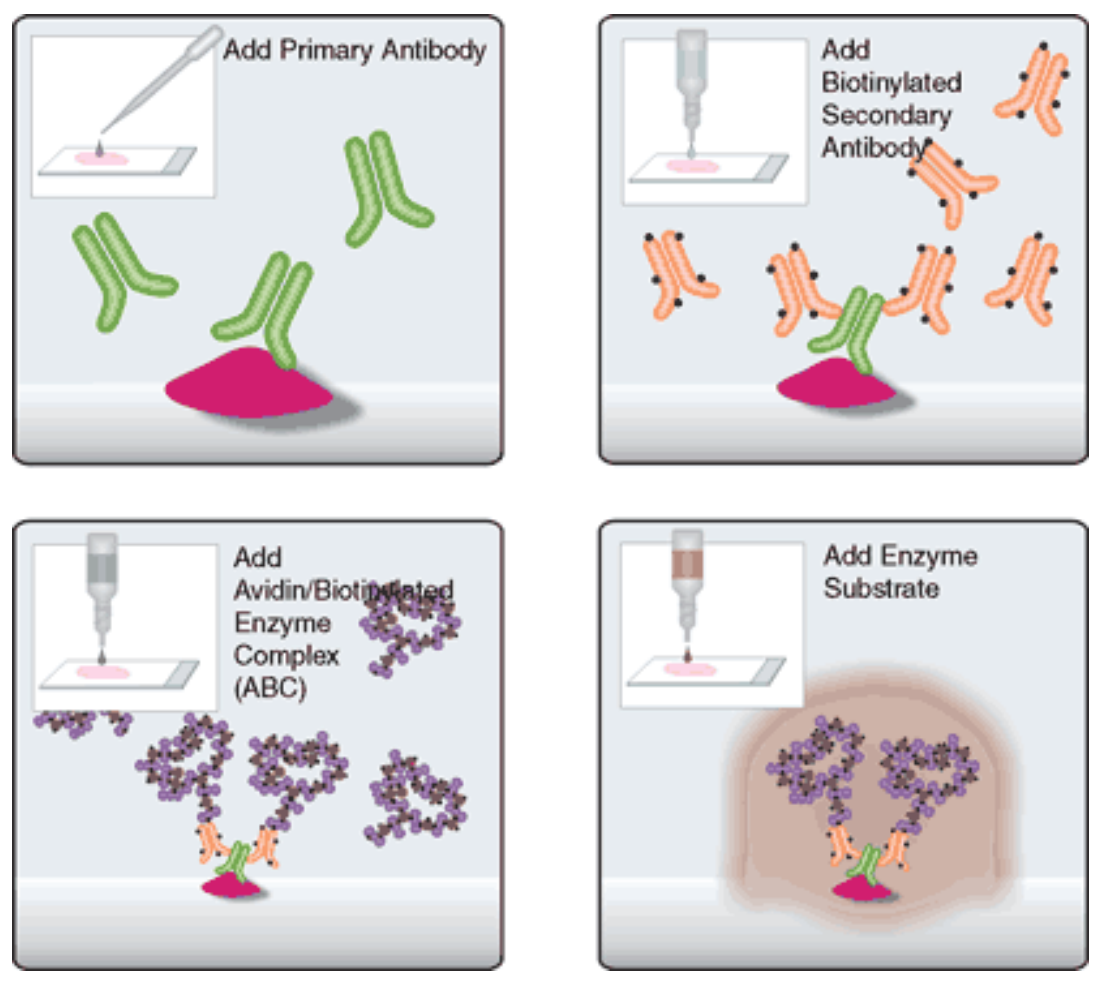

Figure 7. Four primary steps required to perform ELISA. 1) Primary antibody bonds to antigen of interest. 2) Secondary antibody, specific to primary antibody species and Ig super-family bonds to primary antibody. 3) Enzyme complex attaches/engulfs antibody groups. 4) Enzyme substrate bonds to enzyme, marking location and quantity of antigen. (Vectorlabs.com)

The immunohistochemical technique used in this study is a process very similar to that used in classic ELISA. The most obvious difference becomes apparent as the target is considered. This study will use the same protein chain (antibody, antibody, and enzyme) to try to indentify a cytokine in tissue rather than in serum. Such a process is not uncommon and has been used when trying to study BMPs or BMP antagonists in bone and other tissues, including cartilage, neural, lung and pancreatic tissue (Haque, et al., 
2008; Haudenschild, et al., 2004; Koli, et al., 2006; Nakamura, et al., 2003;

Tardif, et al., 2004). This difference should give us information on both location of the target cytokine and concentration, rather than just general concentration, as classic ELISA may be limited.

\section{Study Goals}

This study's primary focus is testing the levels of the BMP antagonists noggin and gremlin as well as measure the osteocyte and lacunar densities by region and quadrant, and to establish the presence, if any, of BMU activity in unloaded murine bone. As BMPs act as local regulators of osteoblast differentiation, varying levels of antagonists could have an effect on the activity of BMPs and therefore osteoblast activity (Balemans \& Van Hul, 2002). If levels of these antagonists are similar in regions or quadrants where osteocyte densities vary, we can infer that osteocyte viability has no direct effect on antagonist expression in unloaded environments. However, if the levels vary, we can infer BMP antagonists are, at least in part, associated with the change in osteocyte viability and possibly by extension involved in the initiation or continued function of BMU remodeling. These would be especially true if the levels of BMP antagonists vary by region or quadrant in a similar pattern as the variation in osteocyte density. We hypothesize that the last scenario will be the correct one. BMP antagonist levels will vary and this variation will coincide with a variation in osteocyte density. We further 
hypothesize that these variations could also contribute into varying levels of BMU activity. If true, management of BMP antagonist levels in response to changes in osteocyte density (by disease, fracture or other reasons) could be a possible treatment for bone healing. The levels of BMP antagonists will be measured by the use of immunohistochemical staining in conjuncture with methyl green staining to help determine osteocyte and lacunar densities. All these measurements will be compared between four anatomic quadrants (cranial, caudal, lateral and medial) as well as three regions (proximal, mid shaft and distal) of the right hind tibia of murine specimen. It should be noted that to the best knowledge of the investigating team, no such previous study has taken place on cortical bone tissue, although transgenic mice who over express gremlin were shown to have lower bone density, higher levels of spontaneous bone fractures, modeling defects in long bones, and severe osteopenia (Gazzerro, et al., 2005). 


\section{Methods}

\section{Research Subjects}

Six C57 Black6 mice (C57BI/6) were procured at 7 to 9 weeks of age (Taconic, Oxnard, CA), housed in microisolation chambers in the University's vivarium, and later sacrificed at 8 to 12 weeks of age. Somerville, et al.(2004) measured several properties indicative of skeletal maturation in C57BI/6 mice including tibial length, porosity and mineral and organic mass. They reported steady values in most coming between 3-4 months of age, with a full skeletal maturation estimate between 3-6 months though by their own admission it is "probably earlier in this time span rather than later". As such, our subjects at 2-3 months of age sit at the border between young adulthood and full maturity (with respect to skeletal development).

\section{Perfusion Fixation}

Each animal was anesthetized with $25 \%$ Avertin $(0.15 \mathrm{ml} / 10 \mathrm{~g})$ given via intraperitoneal injection and placed on a heating pad. The hair was shaved and limbs were taped to the heating pad. The skin was separated from the muscle between the abdomen and thoracic cavity. A thoracotomy was performed and a small incision was made in the left ventricular apex, allowing a vasodilator followed by histochoice to be injected; resulting in fixation of limbs. Once fixed, the right hind tibia were dissected and placed in microcentrifuge tubes with histochoice to post fix at 4 degrees Celsius. 
Hind limb samples were transferred into a decalcification solution to soften the bone prior to embedding for 3 to 4 days. The decalcification solution was composed of 150 grams disodium EDTA dehydrate and 15 grams $\mathrm{NaOH}$. Water was added until the $\mathrm{pH}$ of the solution reached 7.4 (between $700-800 \mathrm{ml}$ ), yielding an approximate 15\% EDTA solution.

\section{Tissue collection and Processing}

Hind legs were collected from sacrificed murine models as per suggested by the University's Institutional Animal Care and Use Committee (IUCAC). Samples were fixed in Histochoice (Amresco) for a period of several days. Histochoice has been shown to be a suitable substitute for the more classically accepted use of formaldehyde when combined with an alkaline phosphatase based immunohistochemical study, providing comparable to improved staining (Kacena, et al., 2004). After fixation, samples were decalcified as stated above, after which they were placed back in histochoice and refrigerated until tissue processing was performed. Tissue samples were cleared and embedded in paraffin using the Shandon Excelsior ES system (Thermo Fisher Scientific, Waltham, MA ). Blocks were then cut into 6 micron thick sections, cut axially, using the Leica RM2255 rotary microtome (Leica Microsystems, Bannockburn, IL ). Tissue samples were then floated in a warm distilled water bath (Boekel Scientific, Feasterville, PA) and attached to slides (Thermo Fisher Scientific) with two sections being 
placed per slide. Slides were allowed to dry at room temperature for approximately 24 hours before staining.

\section{Immunohistochemistry}

Slides were warmed in an incubator at approximately $45-50 \stackrel{\circ}{\mathrm{C}}$ for 10 to 20 minutes, or until the paraffin lost its opacity. Samples were then cleared of wax in a xylene bath for a period of 5 minutes and immediately rehydrated in a graded ethanol series (8 minutes $\mathrm{EtOH} 100 \%, 3$ minutes 95\% EtOH, 3 minutes $80 \% \mathrm{EtOH}, 3$ minutes $70 \% \mathrm{EtOH}, 3$ minutes $50 \% \mathrm{EtOH}$ ) after which they were allowed to air dry for 20 minutes. After drying, slides were washed for 5 minutes in a phosphate buffered saline (PBS) bath. Slides were then incubated in rabbit blocking serum (Vector Laboratories, Burlingame, CA) for 30 minutes (diluted in PBS). After blotting of excess blocking serum, slides were incubated for 30 minutes in either anti-noggin goat polyclonal lgG or anti-gremlin goat polyclonal $\lg G$ at 200 micrograms per milliliter down to 1:50 dilutions (diluted in PBS) (siRNA gene silencers, Santa Cruz Biotechnology, Santa Cruz, CA). Slides were again washed for 5 minutes in PBS, incubated for 30 minutes in an Avidin/Biotinylated enzyme complex specific to goat lgG (Vector Laboratories)(diluted in PBS), washed again for 5 minutes in PBS, and incubated for 30 minutes with the VECTASTAIN® ABC-AP Reagent (Vector Laboratories, kit system specific for goat IgG and alkaline phosphatase). The protein complex was completed with another wash in PBS for 5 minutes followed by 30 minute incubation in the VectaStain Red 
substrate (Vector Laboratories), and a final 5 minute PBS wash. Both the VECTASTAIN® ABC-AP Reagent and VectaStain Red substrate were prepared as instructed by the available company protocols. A $2 \%$ methyl green counterstain was performed immediately after primary staining was completed. The methyl green counterstaining solution was prepared as follows- 2.72 grams of sodium acetate, trihydrate (MW 136.1) (Sigma, St. Louis, MO) was mixed into $200 \mathrm{ml}$ of distilled water. Once dissolved, the $\mathrm{pH}$ was adjusted to 4.2 using concentrated glacial acetic acid (Sigma). Next, 4 grams of methyl green ( $<0.5 \%$ crystal violet) (Sigma) were mixed into $200 \mathrm{ml}$ of the $0.1 \mathrm{M}$ sodium acetate buffer until dissolved. Samples were placed in methyl green for 10 minutes, followed by 10 dips in distilled water and 30 seconds in a fresh distilled water bath. Next, samples were dipped 10 times in n-butanol (Sigma) and then placed in fresh n-butanol (Sigma) for 30 seconds. Slides were then mounted with mounting medium (Thermo Fischer Scientific) and coverslipped.

Control slides were also created following the same procedures as stated above, excluding the administration and incubation with either primary noggin antibody or primary gremlin antibody. It should also be noted that all products obtained from VectorLabs were used at their suggested concentrations, excluding the blocking serum which was used at a higher concentration (double concentration) in order to ensure blocking of nonspecific binding. All incubation times for VectorLabs products were also performed at suggested times; again excluding blocking serum incubation 
time, which was increased from 20 to 30 minutes to ensure blocking. Other procedures follow the general steps of immunohistochemical staining described in literature (such as those of Hedgecock, et al. (2007) and Haudenschild, et al. (2004)) but specifics were developed in house as needed.

To facilitate the analysis, each axial section of bone was divided into four anatomic quadrants: cranial, caudal, medial, and lateral, the equivalent of anterior, posterior, medial, and lateral in a bipedal subject, respectively.

\section{Osteocyte and Lacunar Densities}

To detect the presence and number of viable osteocytes, the methyl green staining protocol was performed as previously stated. Slides were then observed under full-spectrum white light using a BX41 polarizing light microscope (Olympus Optical Co., Ltd., Center Valley, PA) and a Retiga EXi color camera (QImaging, Surrey, BC, Canada). The Q Capture Pro imaging program (Qlmaging) was used in conjunction with the Retiga EXi to capture and catalog images at both $4 x$ magnification and $40 x$ magnification, the former of which is used to capture an image of the entire bone section, the latter of which is used to identify osteocytes and empty lacunae. A Ronchi ruler with known lines at a size of 150 lines per $\mathrm{mm}$ was used to calibrate images at the 40x magnification. Image analysis was performed using ImageJ (Wayne Rasband (NIH)) where images were calibrated according to the above Ronchi ruler, yielding total field dimensions of $0.23 \mathrm{~mm}$ by $0.17 \mathrm{~mm}$. 
From there bone area was measured using the freehand selection tool, giving the area of interest in square millimeters (Figure 8). Positively stained osteocytes were identified when they were: 1) positively stained for the methyl green staining agent and 2) resided within a lacuna with a clearly defined border (Figure 9). It was necessary to only include those cells stained that resided within lacunae to eliminate cells residing in Haversian spaces or those that accidently migrated over bone tissue during the staining procedure. Osteocyte density was then measured both within each of the four quadrants, three regions, as well as the total osteocyte density per subject by dividing the number of positively stained osteocytes by the bone area measured, yielding osteocyte density in number of osteocytes per square millimeter.

Total lacunar density was measured in a similar way. All lacunae observed to contain positively stained osteocytes were counted towards the number of total lacunae in addition to any lacunae with clearly defined boarders not containing positively stained osteocytes. Calculations were then done in the same manner as osteocyte density for the four quadrants, three regions, as well as total density per subject.

Finally, the percentage of lacunae containing viable osteocytes was calculated as the total number of positively stained osteocytes divided by the total number of lacunae for each of the four quadrants, each of the three regions, as well as for each subject. 


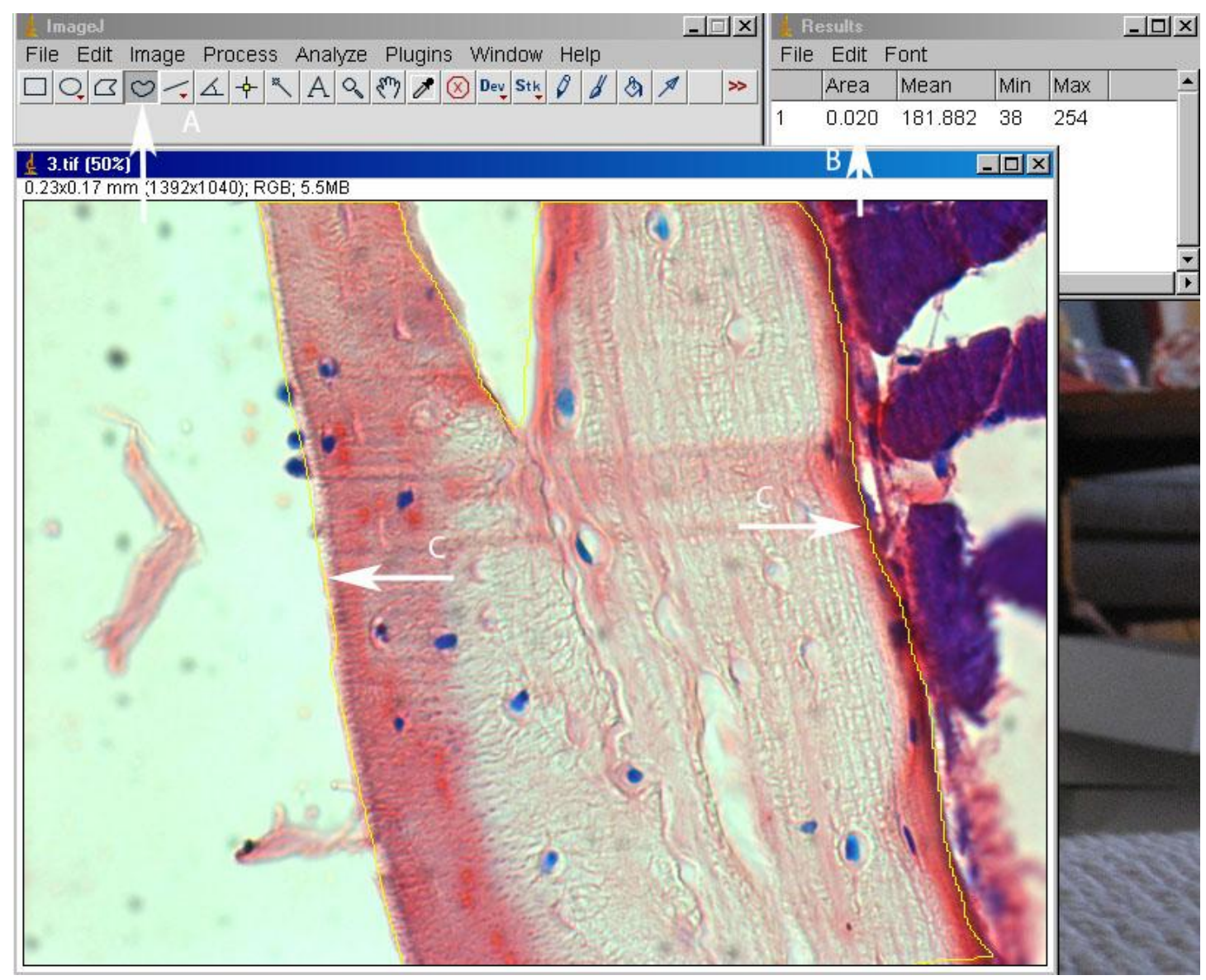

Figure 8. Example of ImageJ measurement of bone area. Note A) freehand tool used to outline bone B) bone area displayed C) complete bone area in image field outlined to keep consistent measurements (boarding yellow line) 


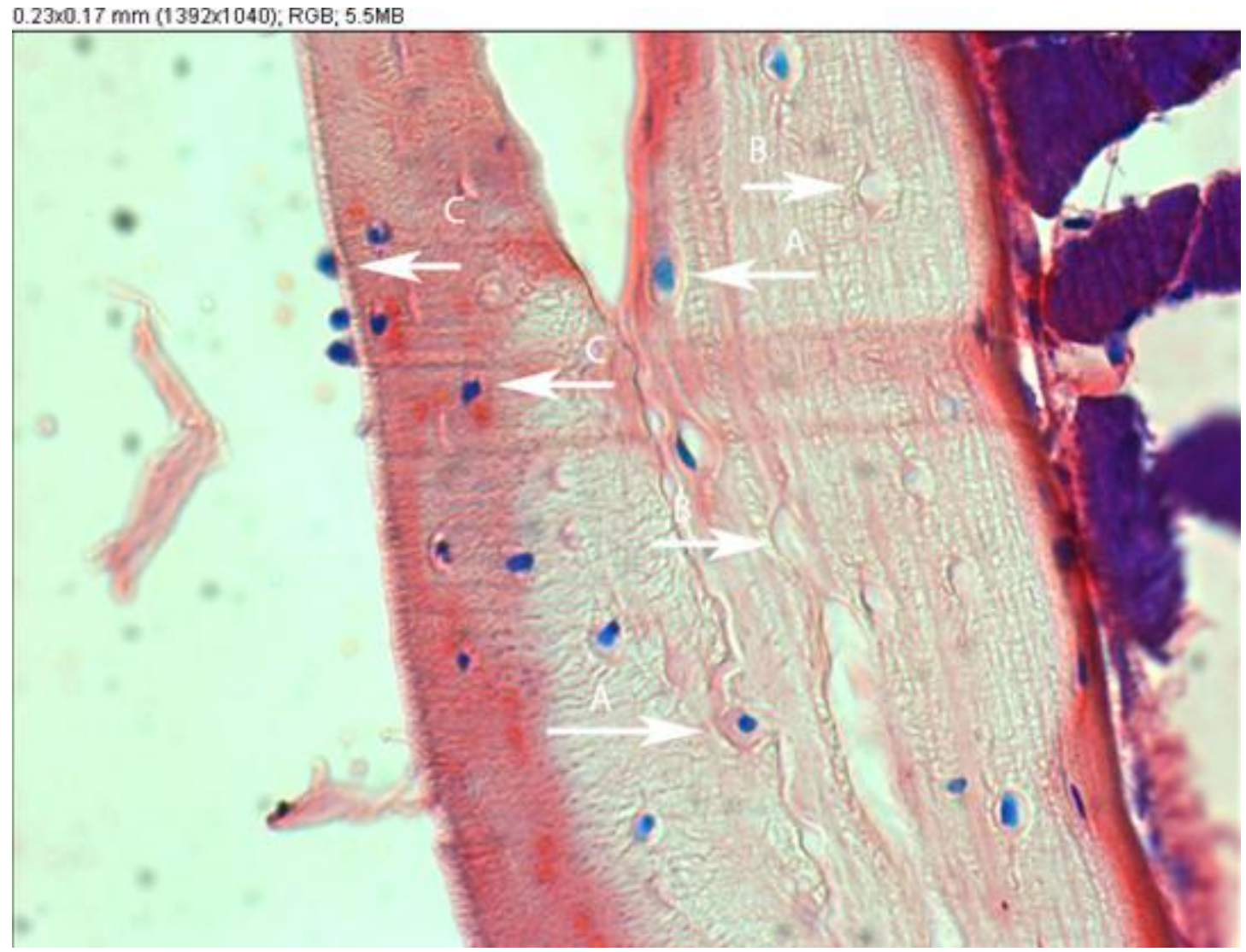

Figure 9. Example of A) positively stained osteocytes residing in lacunae B) negatively stained (empty) lacunae C) non-specifically stained cells (not in lacunae), not counted toward positive osteocyte count

\section{Noggin and Gremlin detection}

To detect the presence and levels of noggin and gremlin in bone, the immunohistochemical staining protocol was performed as previously stated. Slides were then observed under full-spectrum white light using a BX41 polarizing light microscope (Olympus Optical Co., Ltd., Center Valley, PA) and a Retiga EXi color camera (QImaging, Surrey, BC, Canada). The $Q$ Capture Pro imaging program (QImaging) was used in conjunction with the 
Retiga EXi to capture and catalog images at both 4x magnification and 40x magnification, the former of which is used to capture an image of the entire bone section. ImageJ (Wayne Rasband $(\mathrm{NIH})$ ) was used to observe general levels of BMP antagonist present in each 40x magnification image, quantification of which is described in a later section below.

\section{BMU Identification}

BMUs can be visually identified by their distinct shape within the bone matrix. From an axial view point, these identifying features include the comparatively large cavity space left in the osteon as well as the concentric lamellae recently laid down by the osteoblasts. For some active BMUs, we were also able to see the stained nuclei of bundled groups of osteoclasts/osteoblasts but without staining specific for the time period of BMU life span (such as tetracycline double staining), we were unable to identify the time period. For others, we were able to see a clearly defined cement wall with newly formed bone residing within cortical bone (Figure 10). Another example of a BMU, this one in the process of refilling, can be seen in Figure 11. 


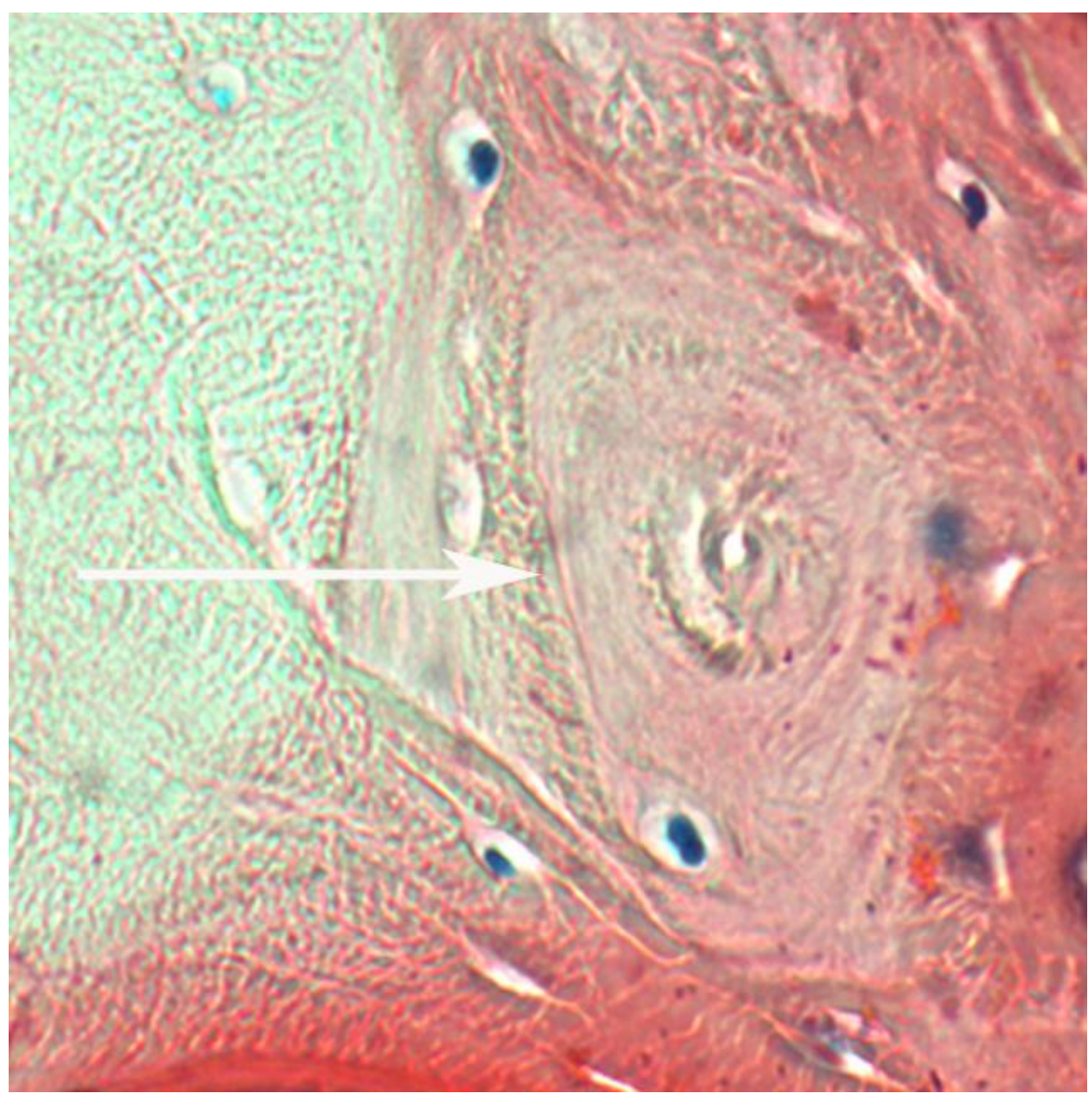

Figure 10. Newly formed osteon residing within hind murine limb. Note the presence of distinct cement line (denote by arrow) bordering newly formed bone. 


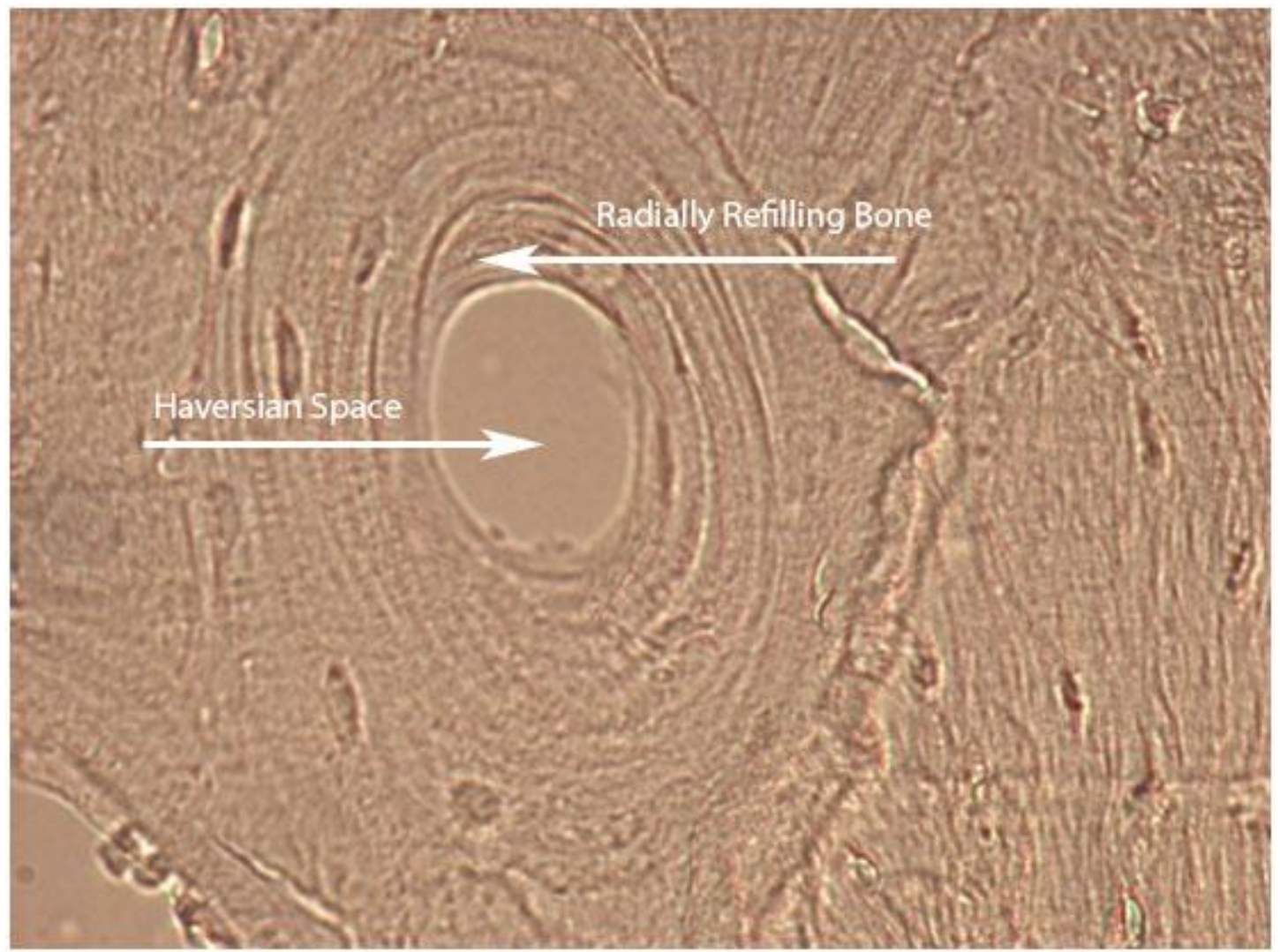

Figure 11. Axial section of a refilling Haversian Basic Multicellular Unit (BMU) found in murine hind tibia. Tissue is unaltered and viewed under white light. Note lamellar bone matrix being refilled by osteoblasts in a radial manner.

\section{Noggin and Gremlin Quantification}

Quantification of both BMP antagonists followed similar procedures of those used by Nakamura, et al., (2003) who quantified BMP receptors and noggin in vertebral samples. Nakamura's group classified the levels of their immunohistochemical staining into five levels: not detectable, trace, weak, moderate, and strong. This study uses the same level system, examples of which can be seen in Figure 12. After initial ratings were assigned to individual 40x magnification images, each rating was attributed a numeric 
value; zero for not detectable, one for trace, two for weak, three for moderate and four for strong. The numeric values allowed for the average staining level (as a numeric value) to be determined for each of the four quadrants and three regions of bone within and between subjects.

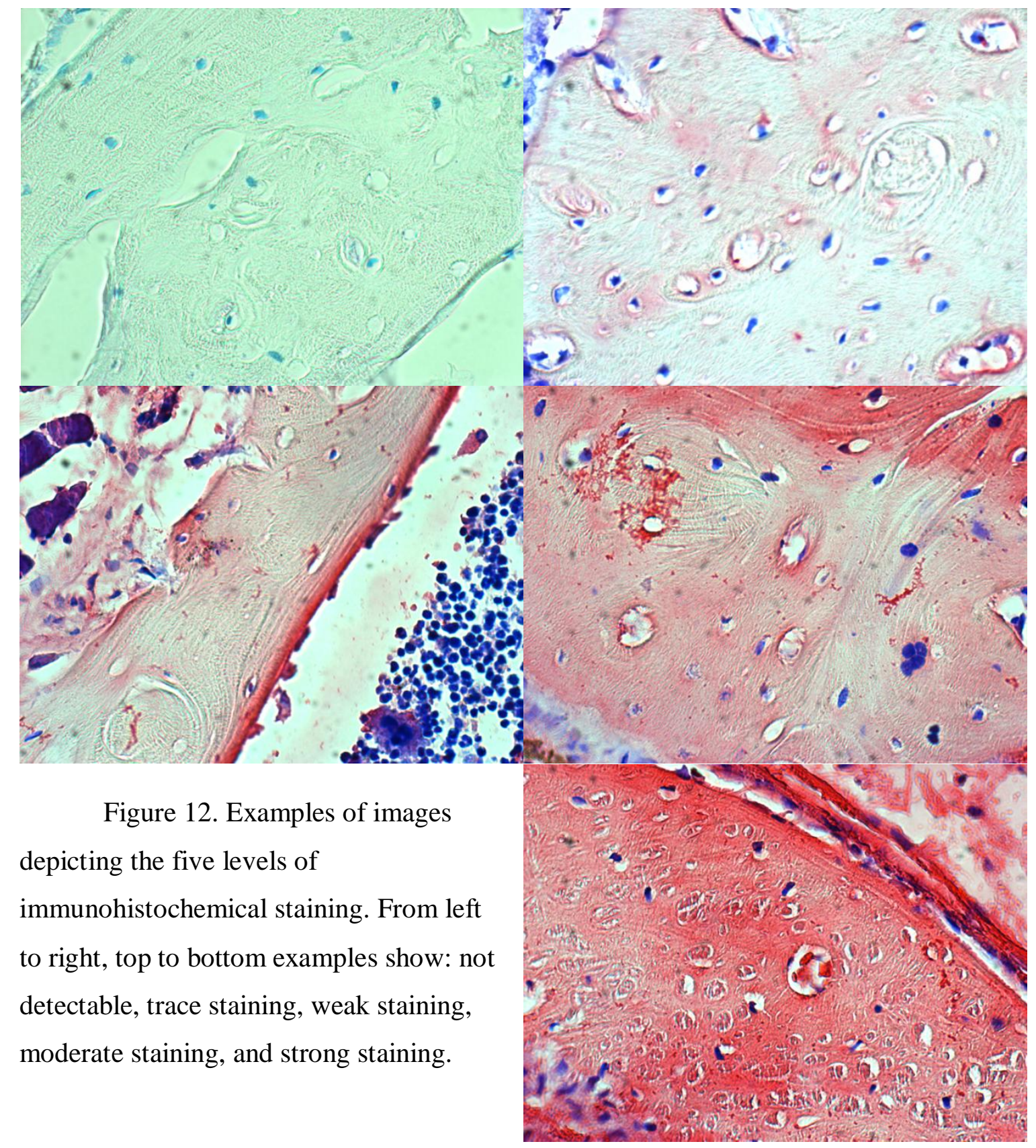




\section{Statistical Methods}

To find differences in osteocyte density, total lacunar density, percentage of lacunae containing viable osteocytes, and the level of BMP antagonists, data was tested using general linear models (GLM, ANOVA) provided in the statistical analysis program Minitab 15 (Minitab). Initially, GLM were performed testing differences with the interaction between the factors of region and quadrant across all subjects. If the interactional factor

was not deemed to be significant $(P>.05)$, region and quadrant were tested individually across all subjects. If either factor was individually found to have significance, post-hoc analysis was performed by Tukey's comparison.

$P$ values less than .05 were deemed significant, while $p$ values less than .15 were deemed to be marginally significant. Residuals for all tests were plotted to determine normality of the data.

Additionally, regression analyses were performed comparing BMP antagonist expression level vs. osteocyte density, lacunar density and the percentage of lacunae containing viable osteocytes at each of the twelve region/quadrant combinations. 


\section{Results}

\section{Osteocyte and Lacunar Densities}

Table 1 below summarizes the findings for osteocyte density (OD), total lacunar density (TLD), and the percentage of lacunae containing viable osteocytes (\%OD/TLD). To verify the validity of the study, the total OD across all subjects was compared to previous studies measuring osteocyte densities. Bucay, et al. (1998) reported osteocyte densities between 750 and 800 per $\mathrm{mm}^{2}$ in tibial mouse diaphysis with the use of $\mathrm{H} \& \mathrm{E}$ staining. Erlebacher, et al. $(1996 ; 1998)$ reported similar numbers, approximately 700 osteocytes per $\mathrm{mm}^{2}$, in the cortical bone from the femoral diaphysis at the level of the third trochanter where periosteal bone resorption was absent, also with the use of H \& E staining. Mullender, et al. (1996) reported slightly higher number in rat femur at $942.8 \mathrm{~mm}^{2}$; however, species and location could both factor into this slightly raised value. Our measurements yielded an OD of 676 with a standard deviation of 80.8. Comparing this result to the studies mentioned above, our OD was significantly lower than the rat model $(p<0.01$; two sample t-test) but was similar to that found in the study by Erlebacher, et al. ( $p>0.60$; two sample t-test). 
Table 3. Osteocyte densities, total lacunar densities, and the percentage of lacunae containing viable osteocytes by individual subjects. Standard deviations in paren.

\begin{tabular}{|ll|lll|}
\hline Subject & $\begin{array}{l}\text { Osteocyte } \\
\text { Density } \\
\left(\mathbf{m m}^{2}\right)\end{array}$ & $\begin{array}{l}\text { Total } \\
\text { Lacunar } \\
\text { Density } \\
\left.\mathbf{( m m}^{2}\right)\end{array}$ & $\begin{array}{l}\text { \% Lacunae } \\
\text { Viable } \\
\text { osteocyte }\end{array}$ & $\begin{array}{l}\text { N (Sample } \\
\text { number) }\end{array}$ \\
\hline 40 & 595 & 838 & 71.0 & 94 \\
42 & 724 & 922 & 78.5 & 439 \\
44 & 625 & 848 & 73.6 & 151 \\
88 & 650 & 862 & 75.4 & 100 \\
90 & 816 & 1009 & 80.8 & 118 \\
93 & 646 & 801 & 80.7 & 400 \\
Overall & $676(80.8)$ & $880(74.5)$ & $76.7(4.00)$ & 1303 \\
\hline
\end{tabular}

Results for differences in OD, TLD, and \%OD/TLD across all subjects with respect to the interaction between quadrant and region can be seen in appendix A. Since no terms were found to be significantly different for any of the three values of interest, differences were tested across all subjects by region and quadrant independently. Mean values and standard deviations for quadrantal data across subjects (Tables 2 and 2a-2c) were calculated from aggregate quadrantal data from all six subjects (Tables 3 through 8 ). Subtables (Tables 2a-2c and 9a-9d) were used in the regression analysis.

Analysis, as seen in Tables 2 and 2a-2c, shows no differences in OD, TLD, nor \%OD/TLD when compared across quadrants, although a marginally significant difference was detected in TLD between the medial and lateral quadrants in the proximal region. 
Table 4. Quadrantal differences of osteocyte density (OD), total lacunar density (TLD), the percentage of lacunae containing viable osteocytes (\%OD/TLD) across all subjects. Standard deviations in parentheses.

\begin{tabular}{|l|l|l|l|}
\hline Quadrant & OD/mm2 & TLD/mm2 & \% OD/TLD \\
\hline Cranial (Cr) & $691(94.5)$ & $891(82.4)$ & $77.4(5.72)$ \\
\hline Caudal (Cd) & $659(87.7)$ & $877(94.0)$ & $75.2(6.45)$ \\
\hline Medial (M) & $648(136)$ & $833(128)$ & $77.4(4.93)$ \\
\hline Lateral (L) & $700(44.0)$ & $932(49.9)$ & $75.3(5.21)$ \\
\hline Cr-Cd & .9372 & .9942 & .8978 \\
\hline Cr-M & .8691 & .7106 & 1.000 \\
\hline Cr-L & .9984 & .8724 & .9093 \\
\hline Cd-M & .9976 & .8446 & .9055 \\
\hline Cd-L & .8793 & .7461 & 1.000 \\
\hline M-L & .7907 & .2898 & .9166 \\
\hline
\end{tabular}

Table 2a. Mean quandrantal data for osteocyte density (OD), total lacunar density (TLD), the percentage of lacunae containing viable osteocytes (\%OD/TLD) across all subjects, data gathered from proximal region only. Standard deviations in parentheses.

\begin{tabular}{|l|l|l|l|}
\hline Quadrant & OD/mm2 & TLD/mm2 & \% OD/TLD \\
\hline Cranial (Cr) & $676(22)$ & $841(33.3)$ & $80.5(.562)$ \\
\hline Caudal (Cd) & $562(28.2)$ & $813(32.4)$ & $69.9(11.1)$ \\
\hline Medial (M) & $594(133)$ & $775(141)$ & $76.2(3.93)$ \\
\hline Lateral (L) & $736(128)$ & $997(183)$ & $74.0(5.89)$ \\
\hline Cr-Cd & .5491 & .9945 & .4286 \\
\hline Cr-M & .5364 & .7686 & .9315 \\
\hline Cr-L & .8883 & .5534 & .7563 \\
\hline Cd-M & 1.000 & .8449 & .6761 \\
\hline Cd-L & .1779 & .3468 & .8696 \\
\hline M-L & .1719 & .1235 & .9669 \\
\hline
\end{tabular}


Table 2b. Mean quandrantal data for osteocyte density (OD), total lacunar density (TLD), the percentage of lacunae containing viable osteocytes (\%OD/TLD) across all subjects, data gathered from midshaft region only. Standard deviations in parentheses.

\begin{tabular}{|l|l|l|l|}
\hline Quadrant & OD/mm2 & TLD/mm2 & \% OD/TLD \\
\hline Cranial (Cr) & $797(65.1)$ & $985(62.1)$ & $80.9(1.50)$ \\
\hline Caudal (Cd) & $743(31.4)$ & $957(36.2)$ & $77.7(.349)$ \\
\hline Medial (M) & $779(172)$ & $965(138)$ & $80.3(6.30)$ \\
\hline Lateral (L) & $727(34.6)$ & $924(39.2)$ & $78.7(.401)$ \\
\hline Cr-Cd & .9381 & .9839 & .7682 \\
\hline Cr-M & .9973 & .9940 & .9975 \\
\hline Cr-L & .8767 & .8661 & .9050 \\
\hline Cd-M & .9796 & .9996 & .8523 \\
\hline Cd-L & .9977 & .9719 & .9876 \\
\hline M-L & .9412 & .9499 & .9588 \\
\hline
\end{tabular}

Table 2c. Mean quandrantal data for osteocyte density (OD), total lacunar density (TLD), the percentage of lacunae containing viable osteocytes (\%OD/TLD) across all subjects, data gathered from distal region only. Standard deviations in parentheses.

\begin{tabular}{|l|l|l|l|}
\hline Quadrant & OD/mm2 & TLD/mm2 & \% OD/TLD \\
\hline Cranial (Cr) & $616(31.5)$ & $874(62.0)$ & $70.5(4.83)$ \\
\hline Caudal (Cd) & $607(129)$ & $799(153)$ & $75.9(1.92)$ \\
\hline Medial (M) & $632(83.0)$ & $858(90.8)$ & $73.6(4.20)$ \\
\hline Lateral (L) & $636(119)$ & $852(211)$ & $75.6(6.66)$ \\
\hline Cr-Cd & .9995 & .9071 & .5448 \\
\hline Cr-M & .9973 & .9987 & .8604 \\
\hline Cr-L & .9943 & .9967 & .5754 \\
\hline Cd-M & .9900 & .9534 & .9306 \\
\hline Cd-L & .9837 & .9656 & .9999 \\
\hline M-L & .9999 & 1.000 & .9467 \\
\hline
\end{tabular}


Table 3. Aggregate data for osteocyte density (OD), total lacunar density (TLD), the percentage of lacunae containing viable osteocytes (\%OD/TLD) for subject 40 .

\begin{tabular}{|l|l|l|l|}
\hline Quadrant & OD/mm2 & TLD/mm2 & $\%$ OD/TLD \\
\hline Cranial (Cr) & 584 & 878 & 66.5 \\
\hline Caudal (Cd) & 602 & 848 & 71.0 \\
\hline Medial (M) & 501 & 711 & 70.4 \\
\hline Lateral (L) & 732 & 963 & 76.1 \\
\hline
\end{tabular}

Table 4. Aggregate data for osteocyte density (OD), total lacunar density (TLD), the percentage of lacunae containing viable osteocytes (\%OD/TLD) for subject 42 .

\begin{tabular}{|l|l|l|l|}
\hline Quadrant & OD/mm2 & TLD/mm2 & \% OD/TLD \\
\hline Cranial (Cr) & 751 & 941 & 79.8 \\
\hline Caudal (Cd) & 721 & 932 & 77.4 \\
\hline Medial (M) & 658 & 868 & 75.8 \\
\hline Lateral (L) & 702 & 896 & 78.4 \\
\hline
\end{tabular}

Table 5. Aggregate data for osteocyte density (OD), total lacunar density (TLD), the percentage of lacunae containing viable osteocytes (\%OD/TLD) for subject 44.

\begin{tabular}{|l|l|l|l|}
\hline Quadrant & OD/mm2 & TLD/mm2 & \% OD/TLD \\
\hline Cranial (Cr) & 661 & 817 & 80.9 \\
\hline Caudal (Cd) & 554 & 862 & 64.3 \\
\hline Medial (M) & 648 & 849 & 76.4 \\
\hline Lateral (L) & 623 & 902 & 69.0 \\
\hline
\end{tabular}


Table 6. Aggregate data for osteocyte density (OD), total lacunar density (TLD), the percentage of lacunae containing viable osteocytes (\%OD/TLD) for subject 88 .

\begin{tabular}{|l|l|l|l|}
\hline Quadrant & OD/mm2 & TLD/mm2 & \% OD/TLD \\
\hline Cranial (Cr) & 616 & 812 & 75.9 \\
\hline Caudal (Cd) & 721 & 925 & 78.0 \\
\hline Medial (M) & 587 & 774 & 75.8 \\
\hline Lateral (L) & 689 & 1005 & 68.6 \\
\hline
\end{tabular}

Table 7. Aggregate data for osteocyte density (OD), total lacunar density (TLD), the percentage of lacunae containing viable osteocytes (\%OD/TLD) for subject 90 .

\begin{tabular}{|l|l|l|l|}
\hline Quadrant & OD/mm2 & TLD/mm2 & \% OD/TLD \\
\hline Cranial (Cr) & 843 & 1029 & 81.9 \\
\hline Caudal (Cd) & 766 & 983 & 77.9 \\
\hline Medial (M) & 901 & 1063 & 84.7 \\
\hline Lateral (L) & 751 & 951 & 79.0 \\
\hline
\end{tabular}

Table 8. Differences in osteocyte density (OD), total lacunar density (TLD), the percentage of lacunae containing viable osteocytes (\%OD/TLD) between quadrants for subject 93 .

\begin{tabular}{|l|l|l|l|}
\hline Quadrant & OD/mm2 & TLD/mm2 & \% OD/TLD \\
\hline Cranial (Cr) & 690 & 868 & 79.5 \\
\hline Caudal (Cd) & 588 & 714 & 82.4 \\
\hline Medial (M) & 595 & 735 & 81.0 \\
\hline Lateral (L) & 702 & 872 & 80.5 \\
\hline
\end{tabular}


Unlike the comparisons made across quadrants, differences became apparent when compared between regions across subject (Tables 9 and 9a9d). Table 9 below shows differences in OD and TLD between the mid shaft and proximal regions, both of which showed higher average values in the mid shaft region. OD was also significantly higher in the mid shaft region as compared to the distal region, with near marginal differences in TLD between the two regions. The distal region also showed significantly lower percentages of lacunae containing viable osteocytes compared to both the proximal and mid shaft regions.

Table 9. Regional differences of osteocyte density (OD), total lacunar density (TLD), the percentage of lacunae containing viable osteocytes (\%OD/TLD) across all subjects. Standard deviations in parentheses.

\begin{tabular}{|l|l|l|l|}
\hline Region & OD/mm2 & TLD/mm2 & \% OD/TLD \\
\hline Proximal (P) & $631(52.8)$ & $808(74.2)$ & $78.3(2.12)$ \\
\hline Mid Shaft (MS) & $730(27.1)$ & $928(26.0)$ & $78.6(1.08)$ \\
\hline Distal (D) & $627(23.6)$ & $858(32.9)$ & $73.9(2.23)$ \\
\hline P-MS & .0111 & .0176 & .9725 \\
\hline P-D & .9819 & .3637 & .0232 \\
\hline MS-D & .0085 & .1614 & .0164 \\
\hline
\end{tabular}


Table 9a. Mean regional data for osteocyte density (OD), total lacunar density (TLD), the percentage of lacunae containing viable osteocytes (\%OD/TLD) across all subjects, data gathered from cranial quadrant only. Standard deviations in parentheses.

\begin{tabular}{|l|l|l|l|}
\hline Region & OD/mm2 & TLD/mm2 & \% OD/TLD \\
\hline Proximal (P) & $676(22)$ & $841(33.3)$ & $80.5(.562)$ \\
\hline Mid Shaft (MS) & $797(65.1)$ & $985(62.1)$ & $80.9(1.50)$ \\
\hline Distal (D) & $616(31.5)$ & $874(62.0)$ & $70.5(4.83)$ \\
\hline P-MS & .0880 & .1276 & .9931 \\
\hline P-D & .3404 & .7876 & .0764 \\
\hline MS-D & .0183 & .1979 & .0682 \\
\hline
\end{tabular}

Table 5. Mean regional data for osteocyte density (OD), total lacunar density (TLD), the percentage of lacunae containing viable osteocytes (\%OD/TLD) across all subjects, data gathered from caudal quadrant only. Standard deviations in parentheses.

\begin{tabular}{|l|l|l|l|}
\hline Region & OD/mm2 & TLD/mm2 & \% OD/TLD \\
\hline Proximal (P) & $562(28.2)$ & $813(32.4)$ & $69.9(11.1)$ \\
\hline Mid Shaft (MS) & $743(31.4)$ & $957(36.2)$ & $77.7(.349)$ \\
\hline Distal (D) & $607(129)$ & $799(153)$ & $75.9(1.92)$ \\
\hline P-MS & .1339 & .3980 & .5087 \\
\hline P-D & .8006 & .9861 & .5986 \\
\hline MS-D & .2748 & .3402 & .9586 \\
\hline
\end{tabular}


Table 9c. Mean regional data for osteocyte density (OD), total lacunar density (TLD), the percentage of lacunae containing viable osteocytes (\%OD/TLD) across all subjects, data gathered from medial quadrant only. Standard deviations in parentheses.

\begin{tabular}{|l|l|l|l|}
\hline Region & OD/mm2 & TLD/mm2 & \% OD/TLD \\
\hline Proximal (P) & $594(133)$ & $775(141)$ & $76.2(3.93)$ \\
\hline Mid Shaft (MS) & $779(172)$ & $965(138)$ & $80.3(6.30)$ \\
\hline Distal (D) & $632(83.0)$ & $858(90.8)$ & $73.6(4.20)$ \\
\hline P-MS & .1867 & .1742 & .7005 \\
\hline P-D & .7419 & .4104 & .7330 \\
\hline MS-D & .4039 & .5389 & .3558 \\
\hline
\end{tabular}

Table 9d. Mean regional data for osteocyte density (OD), total lacunar density (TLD), the percentage of lacunae containing viable osteocytes (\%OD/TLD) across all subjects, data gathered from lateral quadrant only. Standard deviations in parentheses.

\begin{tabular}{|l|l|l|l|}
\hline Region & OD/mm2 & TLD/mm2 & \% OD/TLD \\
\hline Proximal (P) & $736(128)$ & $997(183)$ & $74.0(5.89)$ \\
\hline Mid Shaft (MS) & $727(34.6)$ & $924(39.2)$ & $78.7(.401)$ \\
\hline Distal (D) & $636(119)$ & $852(211)$ & $75.6(6.66)$ \\
\hline P-MS & .9961 & .8949 & .6518 \\
\hline P-D & .5580 & .6064 & .9301 \\
\hline MS-D & .6674 & .8994 & .8292 \\
\hline
\end{tabular}

\section{BMP Antagonist levels}

Results for differences in the level of individual expression of noggin and gremlin are reported here independent of one another across all subjects with respect to the interaction between quadrant and region. As the BMP 
antagonist control subject, the data for subject 40 was omitted. Since no $p$ values for any of the interactive factor terms were found to be significantly different for BMP antagonist levels, differences were tested across all subjects by region and quadrant independently. Regional and quandrantal analysis was performed and can be seen in tables 10,11, 12 and 13. Noggin showed differences both quadrantally and regionally (Tables 10 and 11). Noggin expression was higher in the cranial region as compared to the caudal, as well higher proximally compared to distally and proximally compared to mid shaft. Furthermore, noggin in the distal region showed marginally significantly higher expression compared to mid shaft expression. Gremlin also showed differences between regions with mid shaft showing higher expression than the distal region as well as the proximal region, while no differences in gremlin levels were significant when compared between quadrants (Tables 12 and 13). Again, sub-tables (Tables 10a-10c, 11a-11d, 12a-12c, and 13a-13d) were used in the regression analysis. Tables 14-18 show average BMP antagonist expression for individual subject, with results for subject 42 and 93 split by noggin and gremlin results. 
Table 10. Quadrantal differences in average level of noggin expression between quadrants across all subjects. Standard deviations in parentheses.

\begin{tabular}{|l|l|}
\hline Quadrant & BMPA level \\
\hline Cranial (Cr) & $2.07(.859)$ \\
\hline Caudal (Cd) & $2.27(.878)$ \\
\hline Medial (M) & $2.16(.896)$ \\
\hline Lateral (L) & $2.17(.883)$ \\
\hline Cr-Cd & .0411 \\
\hline Cr-M & .9903 \\
\hline Cr-L & .7458 \\
\hline Cd-M & .2956 \\
\hline Cd-L & .7091 \\
\hline M-L & .9326 \\
\hline
\end{tabular}

Table 6a. Average level of noggin expression between quadrants across all subjects, data gathered from proximal region only. Standard deviations in parentheses.

\begin{tabular}{|l|l|}
\hline Quadrant & BMPA level \\
\hline Cranial (Cr) & $2.33(.844)$ \\
\hline Caudal (Cd) & $2.63(.830)$ \\
\hline Medial (M) & $2.49(.978)$ \\
\hline Lateral (L) & $2.55(.959)$ \\
\hline Cr-Cd & .0685 \\
\hline Cr-M & .7535 \\
\hline Cr-L & .4712 \\
\hline Cd-M & .7787 \\
\hline Cd-L & .9546 \\
\hline M-L & .9819 \\
\hline
\end{tabular}


Table 70b. Average level of noggin expression between quadrants across all subjects, data gathered from mid shaft region only. Standard deviations in parentheses.

\begin{tabular}{|l|l|}
\hline Quadrant & BMPA level \\
\hline Cranial (Cr) & $1.75(.666)$ \\
\hline Caudal (Cd) & $2.00(.721)$ \\
\hline Medial (M) & $2.06(.814)$ \\
\hline Lateral (L) & $1.80(.661)$ \\
\hline Cr-Cd & .3820 \\
\hline Cr-M & .0898 \\
\hline Cr-L & .9035 \\
\hline Cd-M & .8723 \\
\hline Cd-L & .9441 \\
\hline M-L & .6447 \\
\hline
\end{tabular}

Table 8c. Average level of noggin expression between quadrants across all subjects, data gathered from distal region only. Standard deviations in parentheses.

\begin{tabular}{|l|l|}
\hline Quadrant & BMPA level \\
\hline Cranial (Cr) & $2.35(1.10)$ \\
\hline Caudal (Cd) & $1.96(1.04)$ \\
\hline Medial (M) & $1.76(.663)$ \\
\hline Lateral (L) & $2.14(.949)$ \\
\hline Cr-Cd & .0673 \\
\hline Cr-M & .0983 \\
\hline Cr-L & .9761 \\
\hline Cd-M & .9764 \\
\hline Cd-L & .4696 \\
\hline M-L & .6447 \\
\hline
\end{tabular}


Table 91. Regional differences in average level of noggin expression between regions across all subjects. Standard deviations in parentheses.

\begin{tabular}{|l|l|}
\hline Region & BMPA level \\
\hline Proximal (P) & $2.48(.887)$ \\
\hline Mid Shaft (MS) & $2.17(.883)$ \\
\hline Distal (D) & $2.08(.992)$ \\
\hline P-MS & .0000 \\
\hline P-D & .0496 \\
\hline MS-D & .0620 \\
\hline
\end{tabular}

Table 11a. Average level of noggin expression between regions across all subjects, data gathered from cranial quadrant only. Standard deviations in parentheses.

\begin{tabular}{|l|l|}
\hline Region & BMPA level \\
\hline Proximal (P) & $2.33(.844)$ \\
\hline Mid Shaft (MS) & $1.75(.666)$ \\
\hline Distal (D) & $2.35(1.10)$ \\
\hline P-MS & .0000 \\
\hline P-D & .9873 \\
\hline MS-D & .0002 \\
\hline
\end{tabular}


Table 101b. Average level of noggin expression between regions across all subjects, data gathered from caudal quadrant only. Standard deviations in parentheses.

\begin{tabular}{|l|l|}
\hline Region & BMPA level \\
\hline Proximal (P) & $2.63(.830)$ \\
\hline Mid Shaft (MS) & $2.00(.721)$ \\
\hline Distal (D) & $1.96(1.04)$ \\
\hline P-MS & .0000 \\
\hline P-D & .0010 \\
\hline MS-D & .9792 \\
\hline
\end{tabular}

Table 111c. Average level of noggin expression between regions across all subjects, data gathered from medial quadrant only. Standard deviations in parentheses.

\begin{tabular}{|l|l|}
\hline Region & BMPA level \\
\hline Proximal (P) & $2.49(.978)$ \\
\hline Mid Shaft (MS) & $2.06(.814)$ \\
\hline Distal (D) & $1.76(.663)$ \\
\hline P-MS & .0822 \\
\hline P-D & .0032 \\
\hline MS-D & .3828 \\
\hline
\end{tabular}


Table 121d. Aaverage level of noggin expression between regions across all subjects, data gathered from lateral quadrant only. Standard deviations in parentheses.

\begin{tabular}{|l|l|}
\hline Region & BMPA level \\
\hline Proximal (P) & $2.55(.959)$ \\
\hline Mid Shaft (MS) & $1.80(.661)$ \\
\hline Distal (D) & $2.14(.949)$ \\
\hline P-MS & .0003 \\
\hline P-D & .2523 \\
\hline MS-D & .3826 \\
\hline
\end{tabular}

Table 132. Quadrantal differences in average level of gremlin expression between quadrants across all subjects. Standard deviations in parentheses.

\begin{tabular}{|l|l|}
\hline Quadrant & BMPA level \\
\hline Cranial (Cr) & $1.79(.810)$ \\
\hline Caudal (Cd) & $1.74(.849)$ \\
\hline Medial (M) & $1.63(.760)$ \\
\hline Lateral (L) & $1.66(.799)$ \\
\hline Cr-Cd & .4899 \\
\hline Cr-M & .6369 \\
\hline Cr-L & .5127 \\
\hline Cd-M & .9993 \\
\hline Cd-L & .9923 \\
\hline M-L & .9992 \\
\hline
\end{tabular}


Table 142a. Average level of gremlin expression between quadrants across all subjects, data gathered from proximal region only. Standard deviations in parentheses.

\begin{tabular}{|l|l|}
\hline Quadrant & BMPA level \\
\hline Cranial (Cr) & $1.59(.834)$ \\
\hline Caudal (Cd) & $1.47(.728)$ \\
\hline Medial (M) & $1.47(.725)$ \\
\hline Lateral (L) & $1.38(.682)$ \\
\hline Cr-Cd & .7265 \\
\hline Cr-M & .8424 \\
\hline Cr-L & .4525 \\
\hline Cd-M & 1.000 \\
\hline Cd-L & .9397 \\
\hline M-L & .9509 \\
\hline
\end{tabular}

Table 152b. Average level of gremlin expression between quadrants across all subjects, data gathered from mid shaft region only. Standard deviations in parentheses.

\begin{tabular}{|l|l|}
\hline Quadrant & BMPA level \\
\hline Cranial (Cr) & $2.02(.729)$ \\
\hline Caudal (Cd) & $1.98(.878)$ \\
\hline Medial (M) & $1.87(.763)$ \\
\hline Lateral (L) & $1.97(.822)$ \\
\hline Cr-Cd & .8497 \\
\hline Cr-M & .4896 \\
\hline Cr-L & .7487 \\
\hline Cd-M & .4576 \\
\hline Cd-L & .8502 \\
\hline M-L & .2399 \\
\hline
\end{tabular}


Table 12c. Average level of gremlin expression between quadrants across all subjects, data gathered from distal region only. Standard deviations in parentheses.

\begin{tabular}{|l|l|}
\hline Quadrant & BMPA level \\
\hline Cranial (Cr) & $1.00(.000)$ \\
\hline Caudal (Cd) & $1.00(.000)$ \\
\hline Medial (M) & $1.00(.000)$ \\
\hline Lateral (L) & $1.5(.707)$ \\
\hline Cr-Cd & 1.000 \\
\hline Cr-M & 1.000 \\
\hline Cr-L & .1564 \\
\hline Cd-M & 1.000 \\
\hline Cd-L & .2053 \\
\hline M-L & .2641 \\
\hline
\end{tabular}

Table 13. Regional differences in average level of gremlin expression between regions across all subjects. Standard deviations in parentheses.

\begin{tabular}{|l|l|}
\hline Region & BMPA level \\
\hline Proximal (P) & $1.52(.773)$ \\
\hline Mid Shaft (MS) & $1.66(.799)$ \\
\hline Distal (D) & $1.08(.289)$ \\
\hline P-MS & .0000 \\
\hline P-D & .2708 \\
\hline MS-D & .0003 \\
\hline
\end{tabular}


Table 163a. Average level of gremlin expression between regions across all subjects, data gathered from cranial quadrant only. Standard deviations in parentheses.

\begin{tabular}{|l|l|}
\hline Region & BMPA level \\
\hline Proximal (P) & $1.59(.834)$ \\
\hline Mid Shaft (MS) & $2.02(.729)$ \\
\hline Distal (D) & $1.00(.000)$ \\
\hline P-MS & .0000 \\
\hline P-D & .2161 \\
\hline MS-D & .0107 \\
\hline
\end{tabular}

Table 1173b. Average level of gremlin expression between regions across all subjects, data gathered from caudal quadrant only. Standard deviations in parentheses.

\begin{tabular}{|l|l|}
\hline Region & BMPA level \\
\hline Proximal (P) & $1.47(.728)$ \\
\hline Mid Shaft (MS) & $1.98(.878)$ \\
\hline Distal (D) & $1.00(.000)$ \\
\hline P-MS & .0006 \\
\hline P-D & .5891 \\
\hline MS-D & .1037 \\
\hline
\end{tabular}


Table 13c. Average level of gremlin expression between regions across all subjects, data gathered from medial quadrant only. Standard deviations in parentheses.

\begin{tabular}{|l|l|}
\hline Region & BMPA level \\
\hline Proximal (P) & $1.47(.725)$ \\
\hline Mid Shaft (MS) & $1.87(.763)$ \\
\hline Distal (D) & $1.00(.000)$ \\
\hline P-MS & .0739 \\
\hline P-D & .6512 \\
\hline MS-D & .2445 \\
\hline
\end{tabular}

Table 183d. Average level of gremlin expression between regions across all subjects, data gathered from lateral quadrant only. Standard deviations in parentheses.

\begin{tabular}{|l|l|}
\hline Region & BMPA level \\
\hline Proximal (P) & $1.38(.682)$ \\
\hline Mid Shaft (MS) & $1.97(.822)$ \\
\hline Distal (D) & $1.5(.707)$ \\
\hline P-MS & .0038 \\
\hline P-D & .9730 \\
\hline MS-D & .6659 \\
\hline
\end{tabular}

Table 194a. Average noggin expression (BMPA level) between quadrants for subject 42. Standard deviations in parentheses.

\begin{tabular}{|l|l|}
\hline Quadrant & BMPA level \\
\hline Cranial (Cr) & $1.75(.666)$ \\
\hline Caudal (Cd) & $2.01(.726)$ \\
\hline Medial (M) & $2.06(.814)$ \\
\hline Lateral (L) & $1.80(.601)$ \\
\hline
\end{tabular}


Table 204b. Average gremlin expression (BMPA level) between quadrants for subject 42. Standard deviations in parentheses.

\begin{tabular}{|l|l|}
\hline Quadrant & BMPA level \\
\hline Cranial (Cr) & $1.90(.690)$ \\
\hline Caudal (Cd) & $1.80(.885)$ \\
\hline Medial (M) & $1.69(.704)$ \\
\hline Lateral (L) & $1.95(.911)$ \\
\hline
\end{tabular}

Table 15. Average bone morphogenetic protein antagonist expression (BMPA level) between quadrants for subject 44 . Standard deviations in parentheses. Note: Stained for noggin only.

\begin{tabular}{|l|l|}
\hline Quadrant & BMPA level \\
\hline Cranial (Cr) & $1.89(.819)$ \\
\hline Caudal (Cd) & $2.18(.914)$ \\
\hline Medial (M) & $1.63(.770)$ \\
\hline Lateral (L) & $1.88(.900)$ \\
\hline
\end{tabular}

Table 16. Average bone morphogenetic protein antagonist expression (BMPA level) between quadrants for subject 88 . Standard deviations in parentheses. Note:

Stained for noggin only.

\begin{tabular}{|l|l|}
\hline Quadrant & BMPA level \\
\hline Cranial (Cr) & $2.35(1.14)$ \\
\hline Caudal (Cd) & $1.96(1.08)$ \\
\hline Medial (M) & $1.74(.689)$ \\
\hline Lateral (L) & $2.14(.949)$ \\
\hline
\end{tabular}


Table 21. Average bone morphogenetic protein antagonist expression (BMPA level) between quadrants for subject 90. Standard deviations in parentheses. Note: Stained for gremlin only.

\begin{tabular}{|l|l|}
\hline Quadrant & BMPA level \\
\hline Cranial (Cr) & $2.19(.754)$ \\
\hline Caudal (Cd) & $2.30(.684)$ \\
\hline Medial (M) & $2.06(.799)$ \\
\hline Lateral (L) & $2.00(.730)$ \\
\hline
\end{tabular}

Table 18a. Average noggin (BMPA level) between quadrants for subject 93. Standard deviations in parentheses.

\begin{tabular}{|l|l|}
\hline Quadrant & BMPA level \\
\hline Cranial (Cr) & $2.38(.860)$ \\
\hline Caudal (Cd) & $2.65(.726)$ \\
\hline Medial (M) & $2.69(.931)$ \\
\hline Lateral (L) & $2.81(.786)$ \\
\hline
\end{tabular}

Table 228b. Average gremlin (BMPA level) between quadrants for subject 93. Standard deviations in parentheses.

\begin{tabular}{|l|l|}
\hline Quadrant & BMPA level \\
\hline Cranial (Cr) & $1.62(.907)$ \\
\hline Caudal (Cd) & $1.41(.660)$ \\
\hline Medial (M) & $1.44(.700)$ \\
\hline Lateral (L) & $1.25(.645)$ \\
\hline
\end{tabular}




\section{Regression Analysis}

Linear regression analysis of noggin expression versus $\mathrm{OD}$ and the $\% O D / T L D$ both show marginally significant negative correlation in expression associated with increases in density and viablility $\left(\mathrm{R}^{2}=.2159\right.$ and .264$)$ (Table 19, Figures 13 and 15). While a negative correlation was also found between noggin expression and TLD, the relationship was not deemed to be significant (Table 19). Interestingly, the relationships between gremlin expression and OD, TLD and \%OD/TLD all showed positive correlations (significant with respect to OD and \%OD/TLD and marginally significant with respect to TLD) as opposed to the decreases seen in noggin expression $\left(\mathrm{R}^{2}=.5348, .3246\right.$ and .4961) (Table 19, Figures 13-15).

Table 23. Linearly relationships between BMP antagonist expression and OD, TLD and \%OD/TLD.

\begin{tabular}{|l|l|l|l|}
\hline Noggin Expression vs. & OD & TLD & \%OD/TLD \\
\hline Slope & -.0019 & -.0013 & -.0436 \\
\hline $\mathrm{R}^{2}$ & .2159 & .0965 & .264 \\
\hline P value & 0.13 & 0.33 & 0.087 \\
\hline
\end{tabular}

\begin{tabular}{|l|l|l|l|}
\hline Gremlin Expression vs. & OD & TLD & \%OD/TLD \\
\hline Slope & .0036 & .0029 & .0733 \\
\hline $\mathrm{R}^{2}$ & .5348 & .3246 & .4961 \\
\hline P value & 0.007 & 0.053 & 0.01 \\
\hline
\end{tabular}


Figure 13. Regression analysis of BMP expression vs. osteocyte density. Data from proximal region represented with the symbol $\bullet$ (diamond), mid shaft region represent with the symbol $\bullet$ (circle), distal region represented with the symbol $\Delta$ (triangle). Cranial, caudal, medial and lateral points are color as blue, red, green and gold, respectively. All points indicating noggin levels are solid, while all points indicating gremlin levels are shape outlines only.

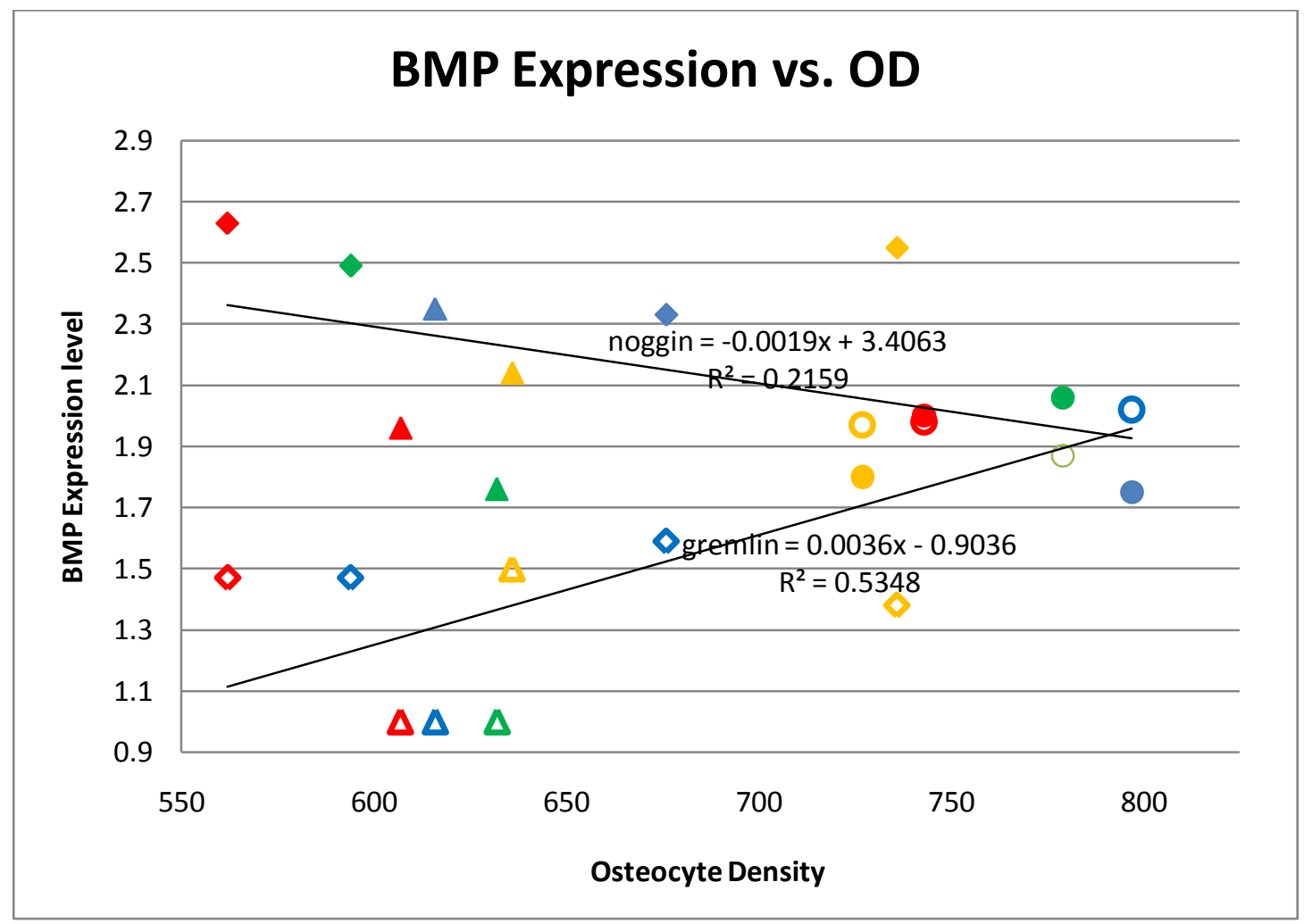


Figure 14. Regression analysis of BMP expression vs. osteocyte density. Data from proximal region represented with the symbol $\downarrow$ (diamond), mid shaft region represent with the symbol $\bullet$ (circle), distal region represented with the symbol $\Delta$ (triangle). Cranial, caudal, medial and lateral points are color as blue, red, green and gold, respectively. All points indicating noggin levels are solid, while all points indicating gremlin levels are shape outlines only.

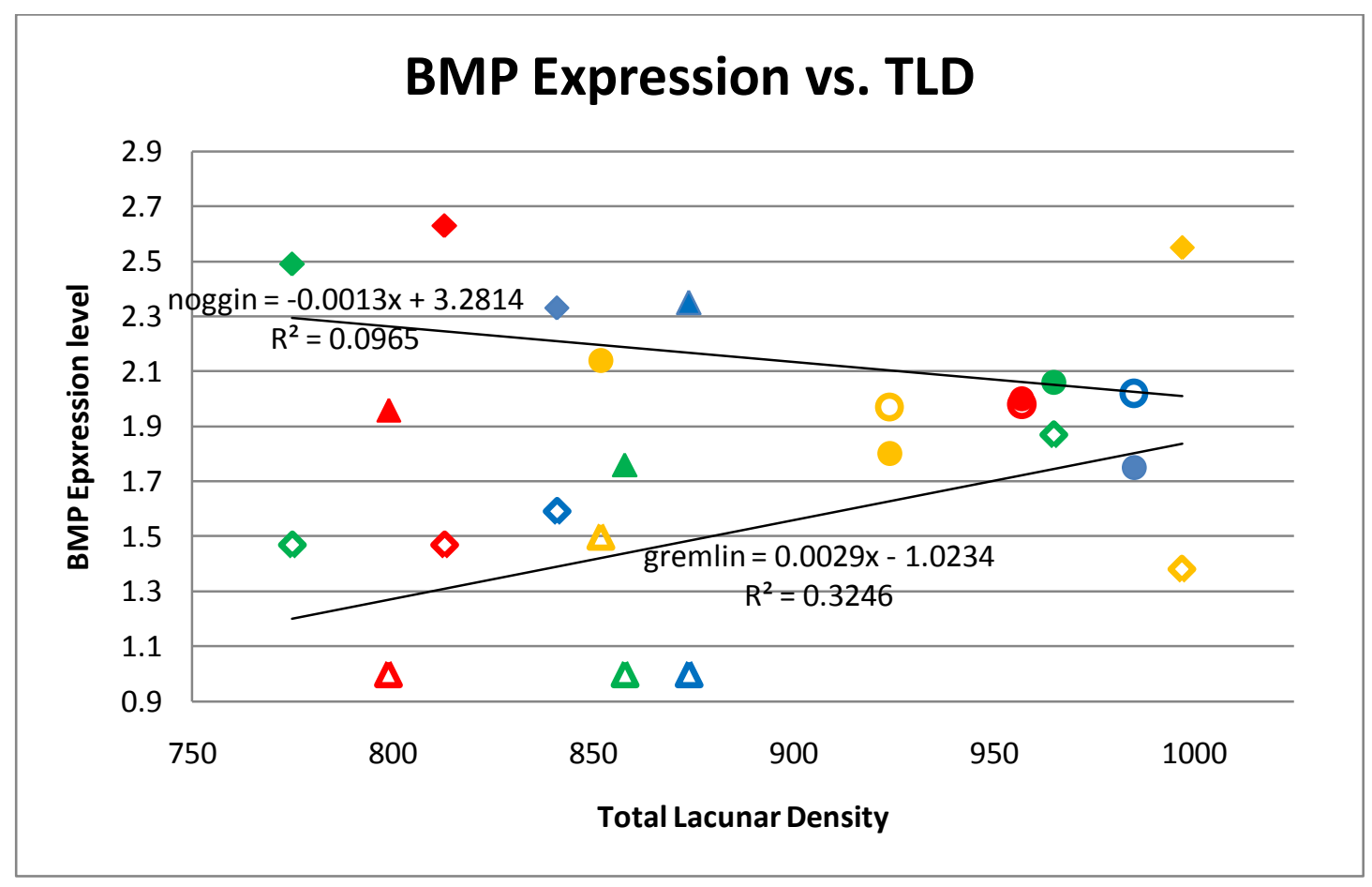


Figure 15. Regression analysis of BMP expression vs. osteocyte density. Data from proximal region represented with the symbol $\downarrow$ (diamond), mid shaft region represent with the symbol $\bullet$ (circle), distal region represented with the symbol $\Delta$ (triangle). Cranial, caudal, medial and lateral points are color as blue, red, green and gold, respectively. All points indicating noggin levels are solid, while all points indicating gremlin levels are shape outlines only.

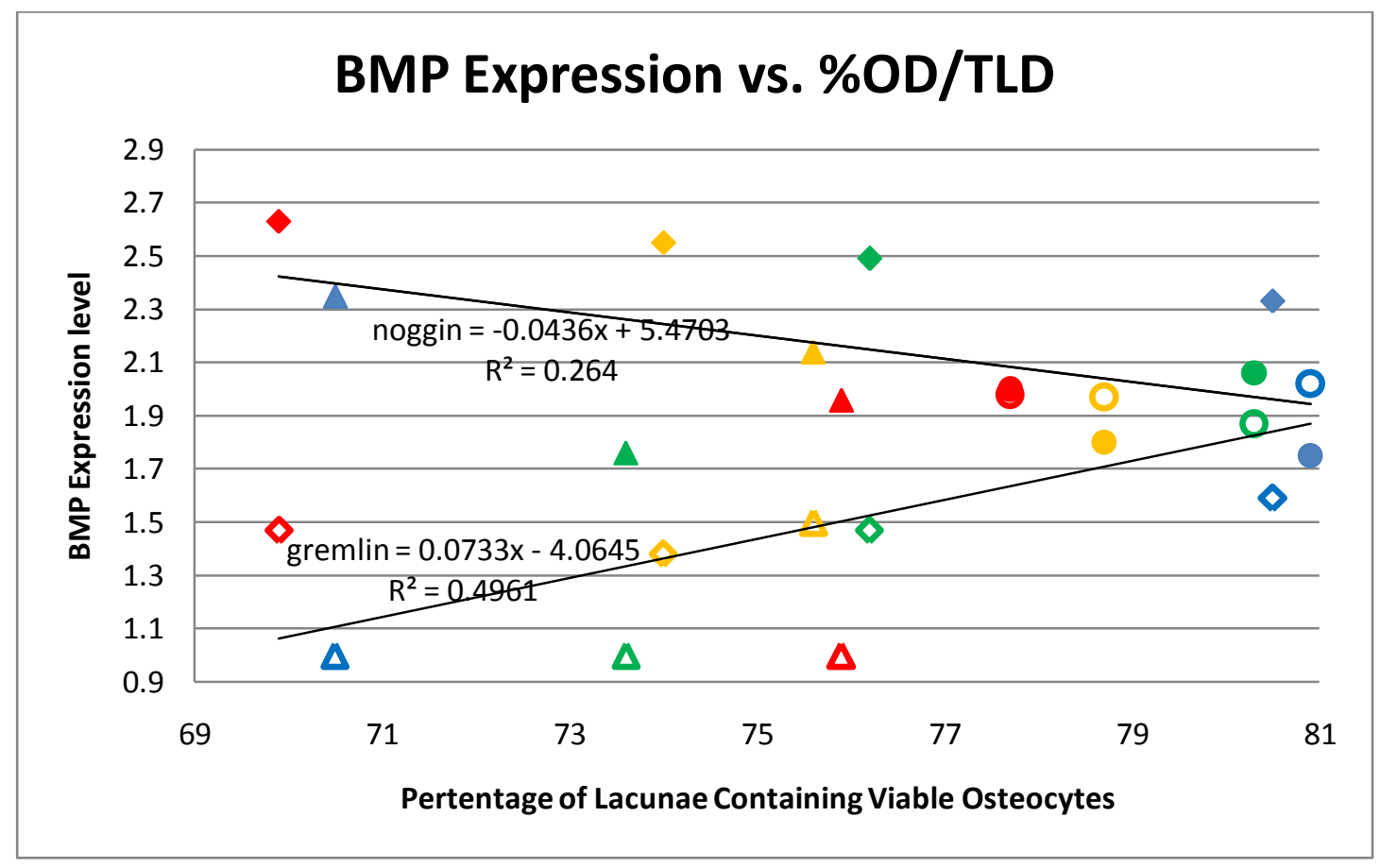

\section{BMU Analysis}

As one would expected of unloaded bone, our samples showed low levels of BMU activity. Because of this, we were unable to confidently perform any statistical analysis by either region or quadrant. Table 20 shows a summary of the number of BMUs positively identified. 
Table 24. Number of BMUs identified across all subjects by both region and quadrant.

\begin{tabular}{|l|l|l|}
\hline Region & Quadrant & BMUs present \\
\hline Proximal & Cranial & 0 \\
\hline Proximal & Caudal & 1 \\
\hline Proximal & Medial & 1 \\
\hline Proximal & Lateral & 1 \\
\hline Mid Shaft & Cranial & 1 \\
\hline Mid Shaft & Caudal & 2 \\
\hline Mid Shaft & Medial & 1 \\
\hline Mid Shaft & Lateral & 0 \\
\hline Distal & Cranial & 0 \\
\hline Distal & Caudal & 0 \\
\hline Distal & Medial & 0 \\
\hline Distal & Lateral & 0 \\
\hline
\end{tabular}




\section{Discussion}

The primary objective of this study was to correlate the levels of the BMP antagonists noggin and gremlin with osteocyte and lacunar densities by region (proximal, mid shaft, and distal) and quadrant (cranial, caudal, medial, and lateral) in unloaded bone to determine if variations in any occur by location, as well as to determine any relationships that exists between BMP antagonist expression and osteocyte and lacunar densities. We hypothesized that varying levels of BMP antagonist expression would coincide with variations in osteocyte density. We also explored the possibility that BMP antagonist, osteocyte density, lacunar density, and the percentage of lacunae containing viable osteocyte vary by either anatomic region, quadrant, or both and expected to see some such variation. These variations, especially if paired together, could point towards a response to varied signals from mechanical stimuli on osteocytes, and in turn the bone remodeling response to such stimuli. We believe there will be a correlation because of the effect BMPs have on osteoblasts (increased activity) and by extension the osteoblastic activity in a BMU. It would follow that with either increased or decreased BMP antagonist expression would factor, at least in part, to increased or decreased inhibition of osteoblastic activity, respectively. Conversely, if expression of the antagonists did not vary at all, we could infer that either osteocyte density does not affect BMP antagonist expression in bone or that some other mechanism or mechanisms are responsible for 
remodeling initiation or continued function. The hind tibia for mouse models were used because mice are relatively cheap and easily obtained and the hind limbs provide much more bone area than the forelimbs.

Many theories put forward the idea that the osteocyte lacunar network plays a critical role in skeletal mechanotransduction. In these hypotheses, osteocytes produce one or more signals that mediate skeletal modeling and/or remodeling, doing so in a dose-dependent manner. Gu et al. (2005) found in culture that osteocyte death stops the inhibition of osteoclasts, in turn triggering local bone resorption, supporting the theory that osteocytes can inhibit bone turnover processes in general. Conversely, other studies have found greater osteocyte and lacunar densities in association with younger, more recently remodeled bone. Power et al. (2002) demonstrated greater levels of lacunae containing osteocytes and greater osteocyte density in bone surrounding forming and resorbing osteons compared with quiescent surfaces in human femoral necks.

Other theories put forth the idea of targeted remodeling, supported by evidence of spatial differences in remodeling within a single bone responding to the uniform stimulus or environment change. Bentolila, et al. (1998) observed spatial differences in bone matrix microdamage in uniformly fatigueloaded ulnar diaphysis of rats. Microdamage occurred principally in medial and lateral ulnar cortices. Furthermore, Bentolila, et al. reported that at 10 days after loading, intracortical resorption was activated and resorption spaces were located principally in the medial and lateral cortices. Emerton, et 
al. (2009) performed ovariectomy on mice models and noted an approximately 2 -fold increase in overall osteocyte apoptosis within the femoral cortex. This osteocyte apoptosis increase was not uniformly distributed throughout the diaphyseal cortex, but instead occurred overwhelmingly in the posterior cortical regions only. The endocortical resorption following surgery occurred only on surfaces near the regions of elevated osteocyte apoptosis, again suggesting spatial remodeling differences. Emerton, et al. concluded that following estrogen loss, osteocyte apoptosis occurs in cortical bone within a discrete and highly consistent area of the cortex that coincides with the region of subsequent increased bone resorption. Noble, et al. (2003) demonstrated that under super-physiologic loads, osteocyte apoptosis is not systemic but highly localized to sites of microdamage that are subsequently remodeled. In 2007, Hedgecock, et al. reported quandrantal and subregional differences in modeling and remodeling parameters, microcrack denities, as well as osteocyte apoptosis in rabbit tibia. Noble \& Reeve (2000) stipulated that osteocytes direct the removal of damaged or redundant bone via mechanisms linked to their own apoptosis or the secretion of cellular attachment proteins although the extent of apoptosis or the pathway of signaling were undetermined. More recent evidence suggests that viable osteocytes produce osteoblastic inhibatory molecules, of which BMP antagonists certainly fall into, as well as other pro-osteclastic factors (Noble, 2008). van Bezooijen, Papapoulos, et al. (2005) specifically showed the upregulation of sclerostin by osteocytes. While scletostin is now 
not considered a classic BMP antagonists it has shown BMP signal inhibition via non-classic BMP antagonist behavoior (van Bezooijen, Papapoulos, et al., 2005). Other research by van Bezooijen and coworkers show evidence that sclerostin production in bone is restriced to only osteocytes, with further evidence suggesting it as a negative regulator of bone formation in both mouse and human bone (van Bezooijen, ten Dijke, et al., 2005).

BMPs have be described as key regulators of bone fracture healing, including initiation, healing speed and healing strength (Dean, et al., 2009). Concurrent research supports the claim by Dean, et al. Yu, et al. found evidence of both BMPs and BMP antagonists in isolated inflammatory cells associated with stabilized fracture healing (2009). They also saw evidence of varying levels of noggin as fracture healing progressed. Noggin was seen in activated periosteal cells 3 days post fracture but not 5 days post fracture, and noted the absence of noggin in endothelial cells associated with new bone in the callus phase of repair. They concluded that the expression of BMP antagonists is closely associated with BMP and bone forming cells.

Mitsui, et al. (2006) noted mechanical stimuli attributed with direct influence of bone remodeling are associated with changes in the homeostasis of hormones in the neighboring areas. Specifically, excessive compressive forces on osteoblasts induce expression of extracellular antagonists of BMPs, inhibiting osteoblastogenesis. Perrien, et al. (2007) showed, in culture, that the addition of the noggin significantly decreased the number of mineralized 
bone nodules in rats, demonstrating that baseline osteoblastogenesis in control medium was dependent on BMP production and function.

BMPs and their antagonists are also believed to play a role in osteoclastogenesis and osteoclastic bone resorption. Okamoto, et al. (2006) found increased bone volume associated with decreased bone formation rate and decreased osteoclast number in mice overexpressing noggin. Wutzl, et al. (2006) demonstrated BMPs 5 and 6 influenced the generation of osteoclasts and that both proteins may be important regulators of bone homeostasis and are candidates for future treatment in bone regeneration. Mishina, et al. (2004) found that young, gene-mutated mice for BMP receptors showed irregular calcification and low bone mass but had normal numbers of osteoblasts. The study also found bone mass was increased in aged mutant mice due to reduced bone resorption associated with reduced bone turnover. With all the research showing interplay between BMPs and BMP antagonists in a variety of bone repair and homeostasis, it would not be improbable to find variation in noggin or gremlin expression as the density of osteocytes change, resulting in changes in bone remodeling parameters.

Our exploratory investigation into regional and quadrantal variation provided several interesting results. Regional analysis between subjects showed the mid shaft having greater osteocyte densities than both the proximal and distal regions in addition to higher total lacunar density in the mid shaft as compared to the proximal region. Interestingly, the mid shaft also had higher gremlin expression than both the proximal and distal regions, 
indicating some relationship. This did not seem to coincide with noggin expression, as antagonist levels showed a hierarchical trend with proximal levels higher than both distal and mid shaft, as well as the mid shaft showing marginally higher levels than the distal. However, these seemingly confounding results were possibility explained when the regression analyses are looked at. Regression analysis for gremlin showed moderate positive linear correlations between expression and osteocyte $\left(R^{2}=.5348, p=0.007\right)$ and lacunar $\left(\mathrm{R}^{2}=.3246, \mathrm{p}=0.053\right)$ densities which coincide with the regional ANOVA relationships found between these same variables. Regression analysis for noggin showed a marginally significant negative linear correlation between expression and osteocyte density $\left(R^{2}=.2159, p=0.13\right)$ explaining the results of the regional ANOVA relationships found for the same variable.

Regional differences were also seen with respect to the percentage of lacunae containing viable osteocytes with the distal region showing lower percentages than both the proximal and mid shaft regions. A significant positive correlation between gremlin expression and viability was seen $\left(R^{2}=\right.$ $.4961, p=0.01$ ), as was a marginally significant negative correlation between noggin expression and viability $\left(R^{2}=.2640, p=0.087\right)$.

Quadrantal analysis showed no differences between any quadrants with respect to osteocyte density, total lacunar density, osteocyte viablilty nor gremlin expression and only a single difference in noggin expression (cranial quadrant showing higher levels than caudal). These corresponding lacks of differences combined with the regional differences reported in osteocyte 
density, lacunar density and antagonist expression confirm our hypothesis and point to relationships in the unloaded conditions.

Other recent studies have shown that osteocyte apoptosis may have a controlling role in the activation of damage induced bone remodeling by indirect methods. Cardoso, et al. (2009) showed that osteocyte apoptosis is necessary to initiate intracortical bone remodeling in response to fatigue microdamage in mature rat ulna, but by what exact mechanism remained unclear. In response to this research, Schaffler, et al., (2010) suggests that viable osteocytes residing near microcracks are actively maintaining life near their apoptotic osteocyte neighbors and that these actively living osteocytes are responsible for the signaling of osteoclasts. The question of how live, dead or both live and dead osteocytes factor into BMU initiation and function, as well as what multitude of signaling factors are involved is a controversial topic and one still under scrutiny.

\section{Limitations}

As previously mentioned, all subjects were housed in the University's vivarium. As such, we were unable to monitor the daily activity level of each individual subject to ensure similar activity levels. We therefore assumed equal activity levels between subjects. If this were not the case, varying activity could result in differing levels of mechanically induced bone remodeling and cytokine release or upkeep, affecting comparisons across subjects. 
While viewing the staining for the immunohistochemical study under white light allowed us to quantify the BMP antagonists with a similar system previously used, other methods unavailable to us may have given additional information. Noggin and gremlin presence may have been more readily detected if used with a Texas red filter system as described by Ermert et al. in (2001) where filtered light (central wavelength, $525 \mathrm{~nm}$; half band width, 10 $\mathrm{nm} \pm 2 \mathrm{~nm}$ ) was used to observe the specific immunohistochemical substrate (VectaStain Red) used in our study. While we cannot know if such a light filtering system could have significantly changed any conclusions drawn here, it is impossible to say it would not. Additionally, time and sample limitations could have affected the immunohistochemical staining as well as the methyl green counterstain. Because of the amount of time each round of staining undertakes and the large amount of samples collected and analyzed, it is possible that daily variations in staining occurred. In an attempt to control this, all staining was performed by only one researcher but it is possible such error could have occurred. Furthermore, bone samples were not processed to include removal of surrounding muscle tissue. This was done for two reasons: first and primarily, this study used subjects in conjunction with several other studies, some of which required the surrounding muscle tissue to remain; secondly and less importantly, while mice tibia are much larger than their associated forearms, they are still very small and would have been hard to indentify while embedded in paraffin, bringing up more possible complications during sectioning. As such, the surrounding muscle tissue was 
also stained, possibly altering the amount of chemicals each individual bone received.

Finally, comparisons for regions (proximal, mid shaft, distal) were impossible to make for individual subjects. When compared across subjects, all three regions were accounted for. However, because of a number of factors, no single subject provided data for all three regions. These factors included: individual occasions where the staining was unsuccessful, leaving "jumps" where bone tissue was unusable; bone sections becoming torn, ripped, folded or otherwise damaged during the sectioning and mounting stages (commonly occurred at the extremes of proximal and distal samples) and again becoming unusable; or "chunking" of samples occurring during sectioning. The chunking mentioned occurred on more than one occasion if the microtome blade initially caught the wax embedded sample improperly or when the microtome was not in proper working function (occurred only once). This lack of complete regional data collection within subjects could also have an impact on analysis across subjects, as individual subject variation could potentially weigh into confirmation or discreditation of hypotheses.

\section{Future Research and Applications}

Bone morphogenetic proteins (BMP) are known to be key regulators of bone fracture healing including initiation, healing speed and healing strength (Dean, et al., 2009). Their role was originally identified in the 1960 s by their ability to induce formation of new bone when implanted at ectopic 
subcutaneous sites in rats (Dean, et al., 2009; Haudenschild, et al., 2004; Rosen, 2006). This study looked at the possible interplay between BMP antagonists and their role in bone remodeling. The idea of local BMP variation leading to a possible mechanism for remodeling of bone could be explained by either a local increase in the levels of BMPs or a local decrease in the levels of BMP antagonists. We tried to investigate this by measuring the levels of two specific BMP antagonists and osteocyte and lacunar densities to see if they varied by bone location. Additionally, since it has been shown that antagonists are products of osteoblasts and are produced as osteoblastic BMPs rise, we also attempted to find a correlation between BMP antagonists and viable osteocytes in varying areas of bone (Gazzerro, et al., 2005; Rosen, 2006). Combined with the relationships found here, data on bone under controlled loading conditions could further expand our understanding of bone remodeling, cell fates and cellular cytokine expression.

Manipulation of BMP and BMP antagonists is still a possible avenue for medical and biologic research and therapy. Research studies have shown that BMPs have some therapeutic effects in both joint disorder and fracture healing (Dean, et al., 2009; Lories, et al., 2005). Whether such therapies are viable or the most effective method of treatment is still yet to be determined. It was the hope that this study could be a step towards further understanding of bone health and remodeling. Our results show some evidence of regional variations and coinciding lacks of quadrantal variations leaving open the possibility that, combined with research under different physiologic conditions, 
these ideas could be taken further. Specfically, comparisons where bone remodeling was induced could show different or stronger variations in antagonist expression and osteocyte densities in response to bone adaptation.

Future research could also include other species. Hedgecock, et al. reported regional differences in bone modeling, remodeling and osteocyte apoptosis in rabbit tibia (2007). By scaling up the size of subject (as compared to mice), they were able to see more evidence of bone remodeling. Further animal testing such as that could eventually lead to human test samples if results were shown to be positive.

We also compared only osteocytes stained as viable in this study, exploring only the possibility that viable osteocytes would be responsible for variations in BMP antagonist levels. It is possible that BMP antagonist levels vary in the presence of recently apoptotic osteocytes as well. Cell death could induce large amounts of BMP antagonist release upon death changing levels in the surrounding tissue. It is also possible cell death could result in cessation of specific protein production as the cell dies, again resulting in changing levels in the surrounding tissue. Additional studies looking into the regional and quadrantal differences in apoptosis could help support claims here and further our understanding. 


\section{Conclusion}

The results of this study show that immunohistochemical processes are a viable way to determine the presence of cytokines in murine bone samples. Because of this, we were able to establish baselines for noggin and gremlin expression in unloaded bone as well as describe their possible relationships with osteocyte density in cortical bone. Further research with super-physiologic loading conditions, resulting in altered cell activity as bone adapts to mechanical environment changes, would provide us with more information on the interplay of osteocytes, BMP antagonist expression and bone remodeling. 


\section{Bibliography}

Ahn, J., Serrano de la Pena, L., Shore, E. M., \& Kaplan, F. S. (2003). Paresis of a bone morphogenetic protein-antagonist response in a genetic disorder of heterotopic skeletogenesis. J Bone Joint Surg Am, 85-A(4), 667-674.

Balemans, W., \& Van Hul, W. (2002). Extracellular regulation of BMP signaling in vertebrates: a cocktail of modulators. Dev Biol, 250(2), 231-250.

Bentolila, V., Boyce, T. M., Fyhrie, D. P., Drumb, R., Skerry, T. M., \& Schaffler, M. B. (1998). Intracortical remodeling in adult rat long bones after fatigue loading. Bone, 23(3), 275-281.

Bucay, N., Sarosi, I., Dunstan, C. R., Morony, S., Tarpley, J., Capparelli, C., et al. (1998). osteoprotegerin-deficient mice develop early onset osteoporosis and arterial calcification. Genes and Development, 12(9), 1260-1268.

Cardoso, L., Herman, B. C., Verborgt, O., Laudier, D., Majeska, R. J., \& Schaffler, M. B. (2009). Osteocyte apoptosis controls activation of intracortical resorption in response to bone fatigue. Journal of Bone and Mineral Research, 24(4), 597-605.

Cuny, G. D., Yu, P. B., Laha, J. K., Xing, X., Liu, J. F., Lai, C. S., et al. (2008). Structure-activity relationship study of bone morphogenetic protein (BMP) signaling inhibitors. Bioorg Med Chem Lett, 18(15), 4388-4392.

Dean, D. B., Watson, J. T., Moed, B. R., \& Zhang, Z. (2009). Role of bone morphogenetic proteins and their antagonists in healing of bone fracture. Front Biosci, 14, 2878-2888.

Emerton, K. B., Hu, B., Woo, A. A., Sinofsky, A., Hernandez, C., Majeska, R. J., et al. (2009). Osteocyte apoptosis and control of bone resorption following ovariectomy in mice. Bone, 46(3), 577-583.

Erlebacher, A., \& Derynck, R. (1996). Increased expression of TGF-beta 2 in osteoblasts results in an osteoporosis-like phenotype. Journal of Cell Biology, 132(1-2), 195-210.

Erlebacher, A., Filvaroff, E. H., Ye, J. Q., \& Derynck, R. (1998). Osteoblastic responses to TGF-beta during bone remodeling. Molecular Biology of the Cell, 9(7), 1903-1918. 
Ermert, L., Hocke, A. C., Duncker, H. R., Seeger, W., \& Ermert, M. (2001). Comparison of different detection methods in quantitative microdensitometry. Am J Pathol, 158(2), 407-417.

Gazzerro, E., Pereira, R. C., Jorgetti, V., Olson, S., Economides, A. N., \& Canalis, E. (2005). Skeletal overexpression of gremlin impairs bone formation and causes osteopenia. Endocrinology, 146(2), 655-665.

Gu, G., Mulari, M., Peng, Z., Hentunen, T. A., \& Vaananen, H. K. (2005). Death of osteocytes turns off the inhibition of osteoclasts and triggers local bone resorption. Biochemical and Biophysical Research Communications, 335(4), 1095-1101.

Hadi, Tamer Mahmoud Abdel (2007). Bone turnover, osteocyte apoptosis, and the basic multicellular unit: a quantitative study of the rabbit tibial mid-diaphysis. UC Davis, Davis, CA.

Haque, T., Hamade, F., Alam, N., Kotsiopriftis, M., Lauzier, D., St-Arnaud, R., et al. (2008). Characterizing the BMP pathway in a wild type mouse model of distraction osteogenesis. Bone, 42(6), 1144-1153.

Haudenschild, D. R., Palmer, S. M., Moseley, T. A., You, Z., \& Reddi, A. H. (2004). Bone morphogenetic protein (BMP)-6 signaling and BMP antagonist noggin in prostate cancer. Cancer Res, 64(22), 8276-8284.

Hedgecock, N. L., Hadi, T., Chen, A. A., Curtiss, S. B., Martin, R. B., \& Hazelwood, S. J. (2007). Quantitative regional associations between remodeling, modeling, and osteocyte apoptosis and density in rabbit tibial midshafts. Bone, 40(3), 627-637.

Jaworski, Z.F.G. (1992). Haversian systems and haversian bone. In Brian Keith Hall (Ed.), Bone: Bone Metabolism and Mineralization (Vol. 4, pp. 21-45). Boca Raton, FL: CRC Press.

Jilka, R. L. (2003). Biology of the basic multicellular unit and the pathophysiology of osteoporosis. Med Pediatr Oncol, 41(3), 182-185.

Kacena, M. A., Troiano, N. W., Coady, C. E., \& Horowitz, M. C. (2004). HistoChoice as an alternative to formalin fixation of undecalcified bone specimens. Biotech Histochem, 79(5-6), 185-190.

Koli, K., Myllarniemi, M., Vuorinen, K., Salmenkivi, K., Ryynanen, M. J., Kinnula, V. L., et al. (2006). Bone morphogenetic protein-4 inhibitor gremlin is overexpressed in idiopathic pulmonary fibrosis. Am J Pathol, 169(1), 61-71. 
Lim, D. A., Tramontin, A. D., Trevejo, J. M., Herrera, D. G., Garcia-Verdugo, J. M., \& Alvarez-Buylla, A. (2000). Noggin antagonizes BMP signaling to create a niche for adult neurogenesis. Neuron, 28(3), 713-726.

Lories, R. J., Daans, M., Derese, I., Matthys, P., Kasran, A., Tylzanowski, P., et al. (2006). Noggin haploinsufficiency differentially affects tissue responses in destructive and remodeling arthritis. Arthritis Rheum, 54(6), 1736-1746.

Lories, R. J., Derese, I., \& Luyten, F. P. (2005). Modulation of bone morphogenetic protein signaling inhibits the onset and progression of ankylosing enthesitis. J Clin Invest, 115(6), 1571-1579.

Manolagas, S. C. (2000). Birth and death of bone cells: basic regulatory mechanisms and implications for the pathogenesis and treatment of osteoporosis. Endocr Rev, 21(2), 115-137.

Marks, S. C., Jr., \& Walker, D. G. (1981). The hematogenous origin of osteoclasts: experimental evidence from osteopetrotic (microphthalmic) mice treated with spleen cells from beige mouse donors. Am J Anat, 161(1), 1-10.

Martin, R. Bruce, Burr, David B., \& Sharkey, Neil A. (1998). Skeletal tissue mechanics. New York: Springer.

Merino, R., Rodriguez-Leon, J., Macias, D., Ganan, Y., Economides, A. N., \& Hurle, J. M. (1999). The BMP antagonist Gremlin regulates outgrowth, chondrogenesis and programmed cell death in the developing limb. Development, 126(23), 5515-5522.

Mishina, Y., Starbuck, M. W., Gentile, M. A., Fukuda, T., Kasparcova, V., Seedor, J. G., et al. (2004). Bone morphogenetic protein type IA receptor signaling regulates postnatal osteoblast function and bone remodeling. Journal of Biological Chemistry, 279(26), 27560-27566.

Mitsui, N., Suzuki, N., Maeno, M., Yanagisawa, M., Koyama, Y., Otsuka, K., et al. (2006). Optimal compressive force induces bone formation via increasing bone morphogenetic proteins production and decreasing their antagonists production by Saos-2 cells. Life Sciences, 78(23), 2697-2706.

Montero, J. A., Lorda-Diez, C. I., Ganan, Y., Macias, D., \& Hurle, J. M. (2008). Activin/TGFbeta and BMP crosstalk determines digit chondrogenesis. Dev Biol, 321(2), 343-356.

Mullender, M. G., Huiskes, R., Versleyen, H., \& Buma, P. (1996). Osteocyte density and histomorphometric parameters in cancellous bone of the 
proximal femur in five mammalian species. Journal of Orthopaedic Research, 14(6), 972-979.

Nakamura, Y., Wakitani, S., Nakayama, J., Wakabayashi, S., Horiuchi, H., \& Takaoka, K. (2003). Temporal and spatial expression profiles of BMP receptors and noggin during BMP-2-induced ectopic bone formation. Journal of Bone and Mineral Research, 18(10), 1854-1862.

Nissim, S., Hasso, S. M., Fallon, J. F., \& Tabin, C. J. (2006). Regulation of Gremlin expression in the posterior limb bud. Dev Biol, 299(1), $12-21$.

Noble, B. S. (2008). The osteocyte lineage. Archives of Biochemistry and Biophysics, 473(2), 106-111.

Noble, B. S., Peet, N., Stevens, H. Y., Brabbs, A., Mosley, J. R., Reilly, G. C., et al. (2003). Mechanical loading: biphasic osteocyte survival and targeting of osteoclasts for bone destruction in rat cortical bone. Am J Physiol Cell Physiol, 284(4), C934-943.

Noble, B. S., \& Reeve, J. (2000). Osteocyte function, osteocyte death and bone fracture resistance. Molecular and Cellular Endocrinology, 159(12), 7-13.

Okamoto, M., Murai, J., Yoshikawa, H., \& Tsumaki, N. (2006). Bone morphogenetic proteins in bone stimulate osteoclasts and osteoblasts during bone development. Journal of Bone and Mineral Research, 21(7), 1022-1033.

Papachroni, K. K., Karatzas, D. N., Papavassiliou, K. A., Basdra, E. K., \& Papavassiliou, A. G. (2009). Mechanotransduction in osteoblast regulation and bone disease. Trends Mol Med, 15(5), 208-216.

Perrien, D. S., Akel, N. S., Dupont-Versteegden, E. E., Skinner, R. A., Siegel, E. R., Suva, L. J., et al. (2007). Aging alters the skeletal response to disuse in the rat. Am J Physiol Regul Integr Comp Physiol, 292(2), R988-996.

Power, J., Loveridge, N., Rushton, N., Parker, M., \& Reeve, J. (2002). Osteocyte density in aging subjects is enhanced in bone adjacent to remodeling haversian systems. Bone, 30(6), 859-865.

Reddi, A. H. (1998). Role of morphogenetic proteins in skeletal tissue engineering and regeneration. Nat Biotechnol, 16(3), 247-252.

Roodman, G. D. (1999). Cell biology of the osteoclast. Exp Hematol, 27(8), 1229-1241. 
Roodman, G. D. (2006). Regulation of osteoclast differentiation. Ann N Y Acad Sci, 1068, 100-109.

Rosen, V. (2006). BMP and BMP inhibitors in bone. Ann N Y Acad Sci, 1068, 19-25.

Schaffler, M. B., D., Kennedy. O., Leong, D. J., Majeska, R. J., Sun, H. B., \& Laudier, D. (2010). Temporal Gene Expression of Key Osteoclast Regulators by Osteocytes in Response to Bone Fatigue in vivo. Paper presented at the Orthopaedic Research Society 2010.

Segovia-Silvestre, T., Neutzsky-Wulff, A. V., Sorensen, M. G., Christiansen, C., Bollerslev, J., Karsdal, M. A., et al. (2009). Advances in osteoclast biology resulting from the study of osteopetrotic mutations. Hum Genet, 124(6), 561-577.

Somerville, J. M., Aspden, R. M., Armour, K. E., Armour, K. J., \& Reid, D. M. (2004). Growth of C57BL/6 mice and the material and mechanical properties of cortical bone from the tibia. Calcified Tissue International, 74(5), 469-475.

Tardif, G., Hum, D., Pelletier, J. P., Boileau, C., Ranger, P., \& Martel-Pelletier, J. (2004). Differential gene expression and regulation of the bone morphogenetic protein antagonists follistatin and gremlin in normal and osteoarthritic human chondrocytes and synovial fibroblasts. Arthritis Rheum, 50(8), 2521-2530.

van Bezooijen, R. L., Papapoulos, S. E., \& Lowik, C. W. (2005). Bone morphogenetic proteins and their antagonists: the sclerostin paradigm. Journal of Endocrinological Investigation, 28(8 Suppl), 15-17.

van Bezooijen, R. L., ten Dijke, P., Papapoulos, S. E., \& Lowik, C. W. (2005). SOST/sclerostin, an osteocyte-derived negative regulator of bone formation. Cytokine and Growth Factor Reviews, 16(3), 319-327.

Wang, Z., Clark, C. C., \& Brighton, C. T. (2006). Up-regulation of bone morphogenetic proteins in cultured murine bone cells with use of specific electric fields. J Bone Joint Surg Am, 88(5), 1053-1065.

Wolff, J. (1986). The Law of Bone Remodeling. Berlin: Springer.

Wutzl, A., Brozek, W., Lernbass, I., Rauner, M., Hofbauer, G., Schopper, C., et al. (2006). Bone morphogenetic proteins 5 and 6 stimulate osteoclast generation. J Biomed Mater Res A, 77(1), 75-83.

Xin, H., Li, Y., Chen, X., \& Chopp, M. (2006). Bone marrow stromal cells induce BMP2/4 production in oxygen-glucose-deprived astrocytes, 
which promotes an astrocytic phenotype in adult subventricular progenitor cells. J Neurosci Res, 83(8), 1485-1493.

Yu, Y. Y., Lieu, S., Lu, C., Miclau, T., Marcucio, R. S., \& Colnot, C. (2009). Immunolocalization of BMPs, BMP antagonists, receptors, and effectors during fracture repair. Bone, 46(3), 841-851. 


\section{Appendix A}

\section{$P$ values for the differences in Osteocyte Density with respect to the}

\section{interaction of regions and quadrants}

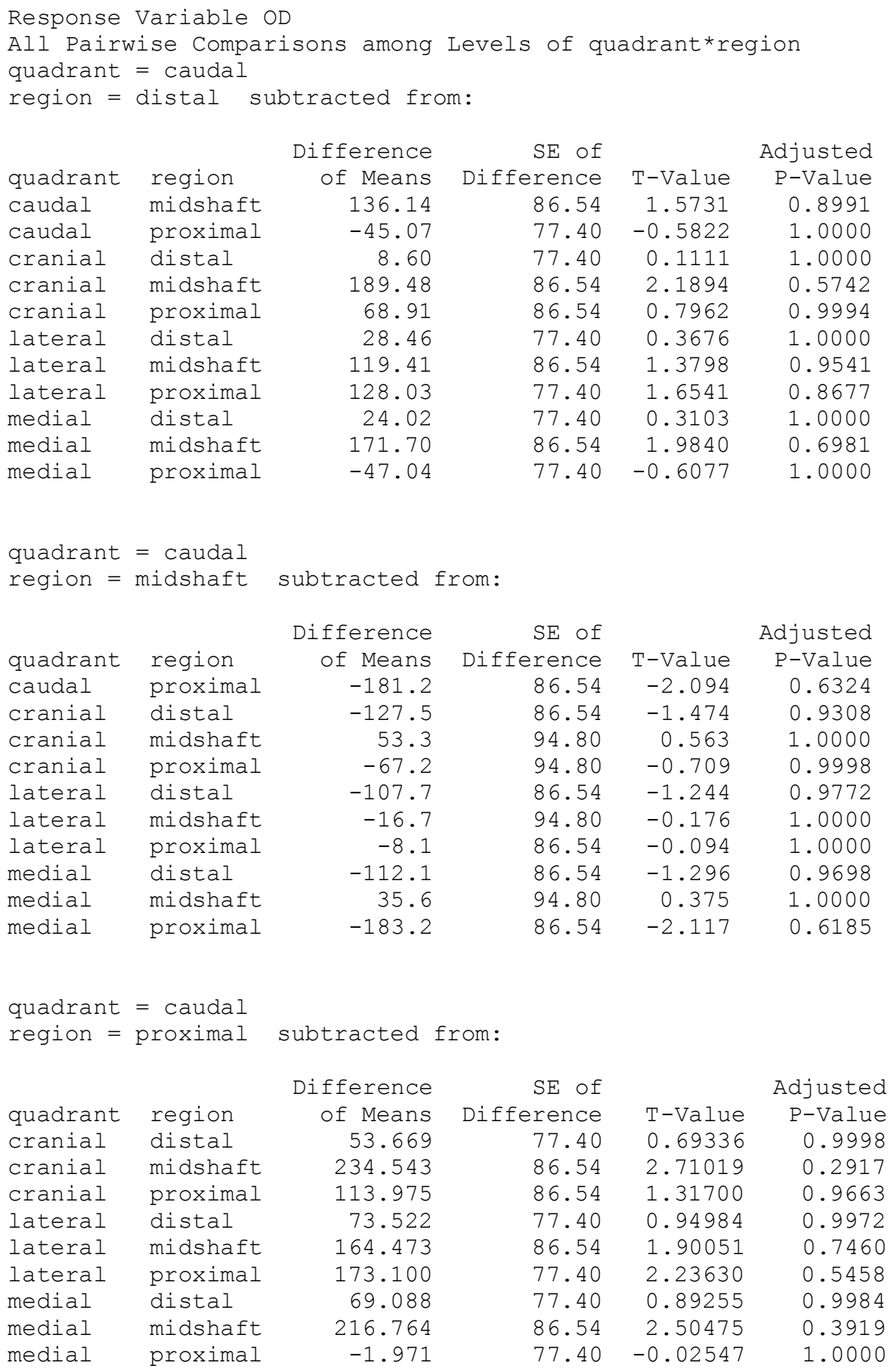




\begin{tabular}{|c|c|c|c|c|c|}
\hline & & Difference & SE of & & Adjusted \\
\hline quadrant & region & of Means & Difference & T-Value & P-Value \\
\hline cranial & midshaft & 180.87 & 86.54 & 2.0900 & 0.6347 \\
\hline cranial & proximal & 60.31 & 86.54 & 0.6968 & 0.9998 \\
\hline lateral & distal & 19.85 & 77.40 & 0.2565 & 1.0000 \\
\hline lateral & midshaft & 110.80 & 86.54 & 1.2804 & 0.9722 \\
\hline lateral & proximal & 119.43 & 77.40 & 1.5429 & 0.909 \\
\hline medial & distal & 15.42 & 77.40 & 0.1992 & 1.000 \\
\hline medial & midshaft & 163.09 & 86.54 & 1.8846 & 0.754 \\
\hline medial & proximal & -55.64 & 77.40 & -0.7188 & 0.999 \\
\hline \multicolumn{6}{|c|}{ quadrant = cranial } \\
\hline \multicolumn{6}{|c|}{ region = midshaft } \\
\hline & & Difference & SE of & & Adjuste \\
\hline quadrant & region & of Means & Difference & T-Value & $\mathrm{P}-\mathrm{Valu}$ \\
\hline cranial & proximal & -120.6 & 94.80 & -1.272 & 0.973 \\
\hline lateral & distal & -161.0 & 86.54 & -1.861 & 0.768 \\
\hline lateral & midshaft & -70.1 & 94.80 & -0.739 & 0.999 \\
\hline lateral & proximal & -61.4 & 86.54 & -0.710 & 0.999 \\
\hline medial & distal & -165.5 & 86.54 & -1.912 & 0.739 \\
\hline medial & midshaft & -17.8 & 94.80 & -0.188 & 1.000 \\
\hline medial & proximal & -236.5 & 86.54 & -2.733 & 0.281 \\
\hline \multicolumn{6}{|c|}{ quadrant $=$ cranial } \\
\hline \multirow[t]{2}{*}{ region = } & proximal & subtracted $f$ & rom: & & \\
\hline & & Difference & SE of & & Adjuste \\
\hline quadrant & region & of Means & Difference & T-Value & $\mathrm{P}-\mathrm{Valu}$ \\
\hline lateral & distal & -40.5 & 86.54 & -0.467 & 1.000 \\
\hline lateral & midshaft & 50.5 & 94.80 & 0.533 & 1.000 \\
\hline lateral & proximal & 59.1 & 86.54 & 0.683 & 0.999 \\
\hline medial & distal & -44.9 & 86.54 & -0.519 & 1.000 \\
\hline medial & midshaft & 102.8 & 94.80 & 1.084 & 0.991 \\
\hline medial & proximal & -115.9 & 86.54 & -1.340 & 0.962 \\
\hline \multicolumn{6}{|c|}{ quadrant = lateral } \\
\hline \multicolumn{6}{|c|}{ region = distal su } \\
\hline & & Difference & SE of & & Adjuste \\
\hline quadrant & region & of Means & Difference & T-Value & $\mathrm{P}-\mathrm{Valu}$ \\
\hline lateral & midshaft & 90.95 & 86.54 & 1.0510 & 0.993 \\
\hline lateral & proximal & 99.58 & 77.40 & 1.2865 & 0.971 \\
\hline dial & distal & -4.43 & 77.40 & -0.0573 & 1.000 \\
\hline dial & midshaft & 143.24 & 86.54 & 1.6552 & 0.867 \\
\hline medial & proximal & -75.49 & 77.40 & -0.9753 & 0.996 \\
\hline \multirow{3}{*}{$\begin{array}{l}\text { quadrant } \\
\text { region = }\end{array}$} & = lateral & & & & \\
\hline & midshaft & subtracted $f$ & rom: & & \\
\hline & & Difference & $\mathrm{SE}$ of & & Adjuste \\
\hline quadrant & region & of Means & Difference & T-Value & $\mathrm{P}-\mathrm{Vall}$ \\
\hline lateral & proximal & 8.6 & 86.54 & 0.100 & 1.000 \\
\hline medial & distal & -95.4 & 86.54 & -1.102 & 0.990 \\
\hline
\end{tabular}




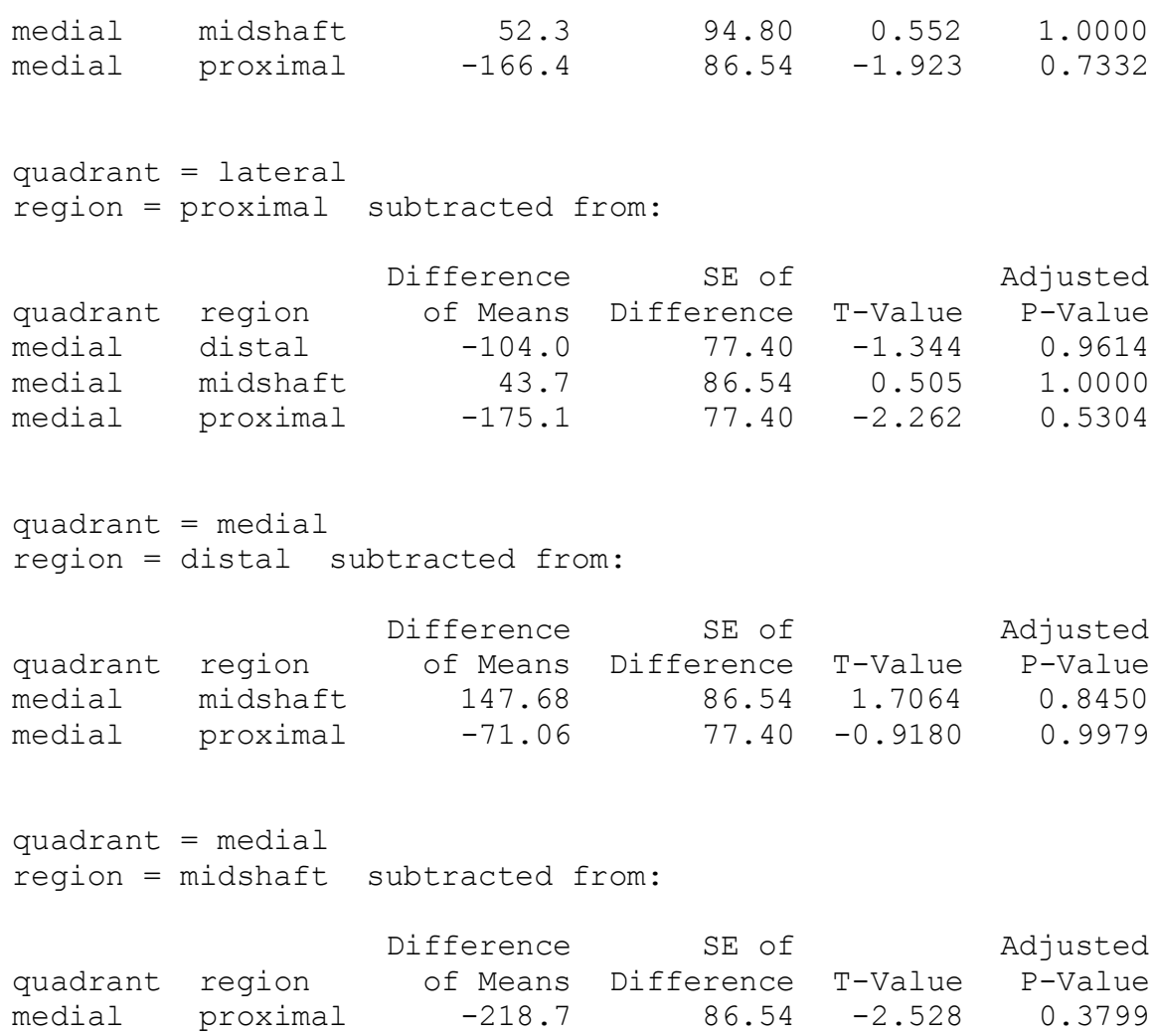

\section{$P$ values for the differences in Total Lacunar Density with respect to the}

\section{interaction of regions and quadrants}

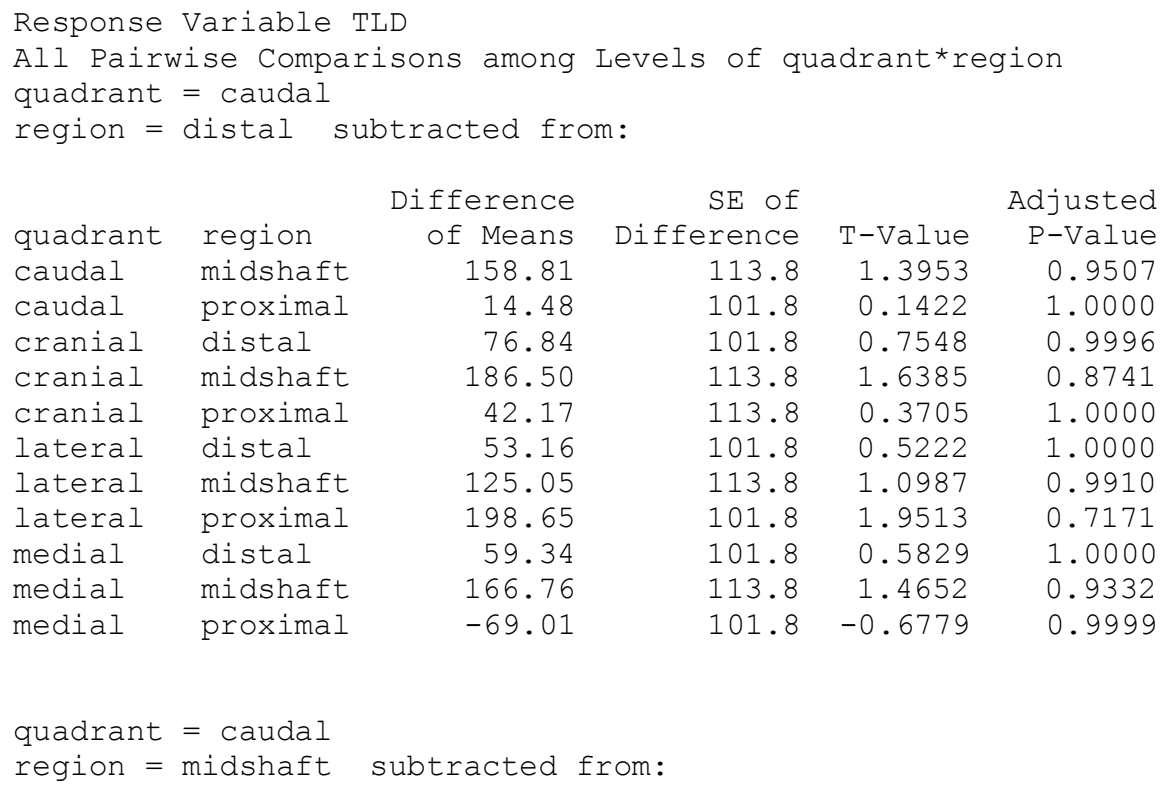




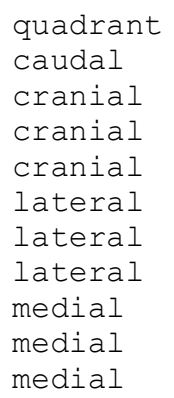

of Means
-144.3
-82.0
27.7
-116.6
-105.6
-33.8
39.8
-99.5
8.0
-227.8

Difference

$$
113.8
$$

T-Value

$-1.268$

$-0.720$

113.8

124.7

0.222

$124.7-0.935$

$113.8-0.928$

$124.7-0.271$

$113.8 \quad 0.350$

$113.8-0.874$

$124.7 \quad 0.064$

$113.8-2.002$

P-Value

0.9740

0.9998

1.0000

0.9976

0.9977

1.0000

1.0000

0.9987

1.0000

0.6878 quadrant = caudal

region = proximal

region
distal
midshaft
proximal
distal
midshaft
proximal
distal
midshaft
proximal

subtracted from:

Difference
of Means
62.36
172.02
27.69
38.68
110.57
184.17
44.86
152.28
-83.49

SE of Difference 101.8

113.8

113.8

101.8

113.8

101.8

101.8

113.8

101.8
T-Value

0.6126

1.5113

0.2433

0.3800

0.9714

1.8091

0.4406

1.3379

$-0.8201$
Adjusted P-Value 1.0000

0.9197

1.0000

1.0000

0.9967

0.7952

1.0000

0.9625

0.9992

quadrant $=$ cranial

region = distal subtracted from:

\begin{tabular}{|c|c|c|c|c|c|}
\hline & & Difference & $\mathrm{SE}$ of & & Adjusted \\
\hline quadrant & region & of Means & Difference & T-Value & P-Value \\
\hline cranial & midshaft & 109.7 & 113.8 & 0.963 & 0.9969 \\
\hline cranial & proximal & -34.7 & 113.8 & -0.305 & 1.0000 \\
\hline lateral & distal & -23.7 & 101.8 & -0.233 & 1.0000 \\
\hline lateral & midshaft & 48.2 & 113.8 & 0.424 & 1.0000 \\
\hline lateral & proximal & 121.8 & 101.8 & 1.197 & 0.9828 \\
\hline medial & distal & -17.5 & 101.8 & -0.172 & 1.0000 \\
\hline nedial & midshaft & 89.9 & 113.8 & 0.790 & 0.9995 \\
\hline nedial & proximal & -145.9 & 101.8 & -1.433 & 0.9418 \\
\hline drant & $=$ cranial & & & & \\
\hline & & Difference & SE of & & Adjusted \\
\hline quadrant & region & of Means & Difference & T-Value & P-Value \\
\hline cranial & proximal & -144.3 & 124.7 & -1.158 & 0.9866 \\
\hline lateral & distal & -133.3 & 113.8 & -1.171 & 0.9853 \\
\hline lateral & midshaft & -61.4 & 124.7 & -0.493 & 1.0000 \\
\hline lateral & proximal & 12.2 & 113.8 & 0.107 & 1.0000 \\
\hline nedial & distal & $-127 \cdot 2$ & 113.8 & -1.117 & 0.9897 \\
\hline medial & midshaft & -19.7 & 124.7 & -0.158 & 1.0000 \\
\hline medial & proximal & -255.5 & 113.8 & -2.245 & 0.5406 \\
\hline drant & $=$ cranial & & & & \\
\hline risn & pros & subtracted $f$ & rom: & & \\
\hline adrant & region & $\begin{array}{l}\text { Difference } \\
\text { of Means }\end{array}$ & $\begin{array}{r}\text { SE of } \\
\text { Difference }\end{array}$ & T-Value & $\begin{array}{l}\text { Adjusted } \\
\text { P-Value }\end{array}$ \\
\hline
\end{tabular}




\begin{tabular}{|c|c|c|c|c|c|}
\hline lateral & distal & 11.0 & 113.8 & 0.0966 & 1.0000 \\
\hline lateral & midshaft & 82.9 & 124.7 & 0.6647 & 0.9999 \\
\hline lateral & proximal & 156.5 & 113.8 & 1.3748 & 0.9552 \\
\hline medial & distal & 17.2 & 113.8 & 0.1508 & 1.000 \\
\hline medial & midshaft & 124.6 & 124.7 & 0.9993 & 0.995 \\
\hline nedial & proximal & $-111 \cdot 2$ & 113.8 & -0.9768 & 0.996 \\
\hline \multirow[t]{2}{*}{$\begin{array}{l}\text { quadrant } \\
\text { region = }\end{array}$} & $\begin{array}{l}=\text { lateral } \\
\text { distal su }\end{array}$ & btracted fro & & & \\
\hline & & Difference & SE of & & Adjuste \\
\hline quadrant & region & of Means & Difference & T-Value & $\mathrm{P}-\mathrm{Val}$ \\
\hline lateral & midshaft & 71.9 & 113.8 & 0.632 & 0.999 \\
\hline lateral & proximal & 145.5 & 101.8 & 1.429 & 0.942 \\
\hline medial & distal & 6.2 & 101.8 & 0.061 & 1.000 \\
\hline medial & midshaft & 113.6 & 113.8 & 0.998 & 0.995 \\
\hline nedial & proximal & $-122 \cdot 2$ & 101.8 & -1.200 & 0.982 \\
\hline \multirow{3}{*}{$\begin{array}{l}\text { quadrant } \\
\text { region = }\end{array}$} & = lateral & & & & \\
\hline & midshaft & subtracted f & rom: & & \\
\hline & & Difference & SE of & & Adjuste \\
\hline quadrant & region & of Means & Difference & T-Value & P-Valy \\
\hline lateral & proximal & 73.6 & 113.8 & 0.647 & 0.999 \\
\hline medial & distal & -65.7 & 113.8 & -0.577 & 1.000 \\
\hline medial & midshaft & 41.7 & 124.7 & 0.335 & 1.000 \\
\hline medial & proximal & $-194 \cdot 1$ & 113.8 & -1.705 & 0.845 \\
\hline \multirow{3}{*}{$\begin{array}{l}\text { quadrant } \\
\text { region = }\end{array}$} & $=$ lateral & & & & \\
\hline & proximal & subtracted $f$ & rom: & & \\
\hline & & Difference & $S E$ of & & Adjuste \\
\hline quadrant & region & of Means & Difference & T-Value & $\mathrm{P}-\mathrm{Val}$ \\
\hline nedial & distal & -139.3 & 101.8 & -1.368 & 0.95 \\
\hline medial & midshaft & -31.9 & 113.8 & -0.280 & 1.000 \\
\hline medial & proximal & -267.7 & 101.8 & -2.629 & 0.325 \\
\hline \multirow{3}{*}{$\begin{array}{l}\text { quadrant } \\
\text { region = }\end{array}$} & $=$ medial & & & & \\
\hline & distal su & btracted fro & & & \\
\hline & & Difference & SE of & & Adjuste \\
\hline quadrant & region & of Means & Difference & T-Value & $\mathrm{P}-\mathrm{Val}$ \\
\hline medial & midshaft & 107.4 & 113.8 & 0.944 & 0.997 \\
\hline medial & proximal & $-128 \cdot 3$ & 101.8 & -1.261 & 0.975 \\
\hline \multirow{2}{*}{$\begin{array}{l}\text { quadrant } \\
\text { region = }\end{array}$} & $=$ medial & & & & \\
\hline & & subtracted $f$ & rom: & & \\
\hline \multirow[b]{2}{*}{$\begin{array}{l}\text { quadrant } \\
\text { medial }\end{array}$} & & Difference & SE of & & Adjuste \\
\hline & $\begin{array}{l}\text { region } \\
\text { proximal }\end{array}$ & $\begin{array}{r}\text { of Means } \\
-235.8\end{array}$ & $\begin{array}{r}\text { Difference } \\
113.8\end{array}$ & $\begin{array}{r}\text { T-Value } \\
-2.071\end{array}$ & $\begin{array}{r}\mathrm{P}-\mathrm{Val} \\
0.64\end{array}$ \\
\hline
\end{tabular}




\title{
$P$ values for the differences in the percentage of lacunae containing viable osteocytes with respect to the interaction of regions and quadrants
}

\author{
Response Variable : viable osteocytes \\ All Pairwise Comparisons among Levels of quadrant*region \\ quadrant $=$ caudal \\ region = distal subtracted from:

quadrant
caudal
caudal
cranial
cranial
cranial
lateral
lateral
lateral
medial
medial
medial

region
midshaft
proximal
distal
midshaft
proximal
distal
midshaft
proximal
distal
midshaft
proximal \\ Difference \\ of Means \\ 0.01812 \\ SE of \\ $-0.05932$ \\ Difference \\ 0.05035 \\ $-0.05312$ \\ 0.04504 \\ 0.05002 \\ 0.04504 \\ 0.04608 \\ 0.05035 \\ $-0.00215$ \\ 0.05035 \\ 0.02837 \\ 0.04504 \\ 0.05035 \\ $-0.01893$ \\ 0.04504 \\ $-0.02296$ \\ 0.04504 \\ 0.04411 \\ 0.05035 \\ 0.00749 \\ 0.04504
T-Value
0.360
$-1.317$
$-1.179$
0.993
0.915
$-0.048$
0.563
$-0.420$
$-0.510$
0.876
0.166 \\ Adjusted \\ P-Value \\ 1.0000 \\ 0.9663 \\ 0.9845 \\ 0.9960 \\ 0.9980 \\ 1.0000 \\ 1.0000 \\ 1.0000 \\ 1.0000 \\ 0.9986 \\ 1.0000 \\ quadrant $=$ caudal \\ region = midshaft subtracted from:

quadrant
caudal
cranial
cranial
cranial
lateral
lateral
lateral
medial
medial
medial

region
proximal
distal
midshaft
proximal
distal
midshaft
proximal
distal
midshaft
proximal \\ Difference \\ of Means \\ $-0.07744$ \\ $-0.07124$ \\ 0.03190 \\ 0.02797 \\ $-0.02026$ \\ 0.01025 \\ $-0.03704$ \\ $-0.04107$ \\ 0.02599 \\ $-0.01062$ \\ SE of \\ Difference \\ 0.05035 \\ 0.05035 \\ 0.05516 \\ 0.05516 \\ 0.05035 \\ 0.05516 \\ 0.05035 \\ 0.05035 \\ 0.05516 \\ 0.05035 \\ T-Value \\ $-1.538$ \\ $-1.415$ \\ 0.578 \\ 0.507 \\ $-0.402$ \\ 0.186 \\ $-0.736$ \\ $-0.816$ \\ 0.471 \\ $-0.211$ \\ Adjusted \\ P-Value \\ 0.9112 \\ 0.9462 \\ 1.0000 \\ 1.0000 \\ 1.0000 \\ 1.0000 \\ 0.9997 \\ 0.9993 \\ 1.0000 \\ 1.0000 \\ quadrant $=$ caudal \\ region = proximal \\ subtracted from:

quadrant
cranial
cranial
cranial
lateral
lateral
lateral
medial
medial
medial

region
distal
midshaft
proximal
distal
midshaft
proximal
distal
midshaft
proximal \\ Difference \\ of Means \\ 0.006199 \\ SE of
Difference \\ 0.109341 \\ 0.105405 \\ 0.057174 \\ 0.087691 \\ 0.040392 \\ 0.036362 \\ 0.103430 \\ 0.066815 \\ 0.04504 \\ 0.05035 \\ 0.05035 \\ 0.04504 \\ 0.05035 \\ 0.04504 \\ 0.04504 \\ 0.05035 \\ 0.04504 \\ T-Value \\ 0.1376 \\ 2.1714 \\ 2.0932 \\ 1.2694 \\ 1.7415 \\ 0.8968 \\ 0.8073 \\ 2.0540 \\ 1.4835 \\ Adjusted \\ P-Value \\ 1.0000 \\ 0.5852 \\ 0.6327 \\ 0.9738 \\ 0.8287 \\ 0.9983 \\ 0.9993 \\ 0.6564 \\ 0.9280 \\ quadrant $=$ cranial \\ region = distal subtracted from:
}

Difference

SE of

Adjusted 


\begin{tabular}{|c|c|c|c|c|c|}
\hline quadrant & region & of Means & Difference & T-Value & P-Value \\
\hline cranial & midshaft & 0.10314 & 0.05035 & 2.0483 & \\
\hline cranial & proximal & 0.09921 & 0.05035 & 1.9701 & 0.7062 \\
\hline lateral & distal & 0.05097 & 0.04504 & 1.1318 & 0.9887 \\
\hline lateral & midshaft & 0.08149 & 0.05035 & 1.6184 & 0.882 \\
\hline lateral & proximal & 0.03419 & 0.04504 & 0.7592 & 0.999 \\
\hline medial & distal & 0.03016 & 0.04504 & 0.6697 & 0.999 \\
\hline medial & midshaft & 0.09723 & 0.05035 & 1.9309 & 0.728 \\
\hline medial & proximal & 0.06062 & 0.04504 & 1.3459 & 0.961 \\
\hline \multirow{3}{*}{$\begin{array}{l}\text { quadrant } \\
\text { region = }\end{array}$} & $=$ cranial & & & & \\
\hline & midshaft & subtracted $\mathrm{f}$ & rom: & & \\
\hline & & Difference & SE of & & Adjuste \\
\hline quadrant & region & of Means & Difference & T-Value & $\mathrm{P}-\mathrm{Vall}$ \\
\hline cranial & proximal & -0.00394 & 0.05516 & -0.071 & 1.000 \\
\hline lateral & distal & -0.05217 & 0.05035 & -1.036 & 0.994 \\
\hline lateral & midshaft & -0.02165 & 0.05516 & -0.392 & 1.000 \\
\hline lateral & proximal & -0.06895 & 0.05035 & -1.369 & 0.956 \\
\hline medial & distal & -0.07298 & 0.05035 & -1.449 & 0.937 \\
\hline medial & midshaft & -0.00591 & 0.05516 & -0.107 & 1.000 \\
\hline medial & proximal & -0.04253 & 0.05035 & -0.845 & 0.999 \\
\hline \multirow{3}{*}{$\begin{array}{l}\text { quadrant } \\
\text { region = }\end{array}$} & $=$ cranial & & & & \\
\hline & proximal & subtracted $\mathrm{f}$ & rom: & & \\
\hline & & Difference & SE of & & Adjust \\
\hline quadrant & region & of Means & Difference & T-Value & $\mathrm{P}-\mathrm{Val}$ \\
\hline lateral & distal & -0.04823 & 0.05035 & -0.958 & 0.997 \\
\hline lateral & midshaft & -0.01771 & 0.05516 & -0.321 & 1.000 \\
\hline lateral & proximal & -0.06501 & 0.05035 & -1.291 & 0.970 \\
\hline medial & distal & -0.06904 & 0.05035 & -1.371 & 0.956 \\
\hline medial & midshaft & -0.00197 & 0.05516 & -0.036 & 1.000 \\
\hline medial & proximal & -0.03859 & 0.05035 & -0.766 & 0.999 \\
\hline \multirow{3}{*}{$\begin{array}{l}\text { quadrant } \\
\text { region = }\end{array}$} & $=$ lateral & & & & \\
\hline & distal su & ubtracted fro & & & \\
\hline & & Difference & SE of & & Adjuste \\
\hline quadrant & region & of Means & Difference & T-Value & $\mathrm{P}-\mathrm{Val}$ \\
\hline lateral & midshaft & 0.03052 & 0.05035 & 0.6060 & 1.000 \\
\hline lateral & proximal & -0.01678 & 0.04504 & -0.3726 & 1.000 \\
\hline medial & distal & -0.02081 & 0.04504 & -0.4621 & 1.000 \\
\hline medial & midshaft & 0.04626 & 0.05035 & 0.9186 & 0.997 \\
\hline medial & proximal & 0.00964 & 0.04504 & 0.2141 & 1.000 \\
\hline \multirow{3}{*}{$\begin{array}{l}\text { quadrant } \\
\text { region = }\end{array}$} & $=$ lateral & & & & \\
\hline & midshaft & subtracted $f$ & rom: & & \\
\hline & & Difference & SE of & & Adjuste \\
\hline quadrant & region & of Means & Difference & T-Value & $\mathrm{P}-\mathrm{Val}$ \\
\hline lateral & proximal & -0.04730 & 0.05035 & -0.939 & 0.997 \\
\hline dial & distal & -0.05133 & 0.05035 & -1.019 & 0.995 \\
\hline lial & midshaft & 0.01574 & 0.05516 & 0.285 & 1.000 \\
\hline dial & proximal & -0.02088 & 0.05035 & -0.415 & 1.000 \\
\hline
\end{tabular}




\begin{tabular}{|c|c|c|c|c|c|}
\hline $\begin{array}{l}\text { quadrant } \\
\text { medial } \\
\text { medial } \\
\text { medial }\end{array}$ & $\begin{array}{l}\text { region } \\
\text { distal } \\
\text { midshaft } \\
\text { proximal }\end{array}$ & $\begin{array}{r}\text { Difference } \\
\text { of Means } \\
-0.004030 \\
0.063038 \\
0.026423\end{array}$ & $\begin{array}{r}\text { SE of } \\
\text { Difference } \\
0.04504 \\
0.05035 \\
0.04504\end{array}$ & $\begin{array}{r}T-\text { Value } \\
-0.08948 \\
1.25188 \\
0.58667\end{array}$ & $\begin{array}{r}\text { Adjusted } \\
\text { P-Value } \\
1.0000 \\
0.9762 \\
1.0000\end{array}$ \\
\hline $\begin{array}{l}\text { quadrant } \\
\text { region = }\end{array}$ & $\begin{array}{l}=\text { medial } \\
\text { distal su }\end{array}$ & tracted fro & & & \\
\hline $\begin{array}{l}\text { quadrant } \\
\text { medial } \\
\text { medial }\end{array}$ & $\begin{array}{l}\text { region } \\
\text { midshaft } \\
\text { proximal }\end{array}$ & $\begin{array}{r}\text { Difference } \\
\text { of Means } \\
0.06707 \\
0.03045\end{array}$ & $\begin{array}{r}\text { SE of } \\
\text { Difference } \\
0.05035 \\
0.04504\end{array}$ & $\begin{array}{r}\text { T-Value } \\
1.3319 \\
0.6762\end{array}$ & $\begin{array}{r}\text { Adjusted } \\
\text { P-Value } \\
0.9636 \\
0.9999\end{array}$ \\
\hline $\begin{array}{l}\text { quadrant } \\
\text { region = }\end{array}$ & $\begin{array}{l}=\text { medial } \\
\text { midshaft }\end{array}$ & subtracted $f$ & com: & & \\
\hline $\begin{array}{l}\text { quadrant } \\
\text { medial }\end{array}$ & $\begin{array}{l}\text { region } \\
\text { proximal }\end{array}$ & $\begin{array}{r}\text { Difference } \\
\text { of Means } \\
-0.03662\end{array}$ & $\begin{array}{r}S E \text { of } \\
\text { Difference } \\
0.05035\end{array}$ & $\begin{array}{l}\text { T-Value } \\
-0.7271\end{array}$ & $\begin{array}{r}\text { Adjusted } \\
\text { P-Value } \\
0.9997\end{array}$ \\
\hline
\end{tabular}

